University of South Florida

DIGITAL COMMONS

Digital Commons @ University of

@ UNIVERSITY OF SOUTH FLORIDA

South Florida

\title{
Requirement of Minimal Signal-to-noise Ratios of Ocean Color Sensors and Uncertainties of Ocean Color Products
}

\author{
Lin Qi \\ Xiamen University \\ Zhongping Lee \\ University of Massachusetts Boston \\ Chuanmin $\mathrm{Hu}$ \\ University of South Florida, huc@usf.edu \\ Menghua Wang \\ National Oceanic and Atmospheric Administrations, Center for Satellite Applications and Research, \\ College Park, Maryland, USA
}

Follow this and additional works at: https://digitalcommons.usf.edu/msc_facpub

Part of the Life Sciences Commons

\section{Scholar Commons Citation}

Qi, Lin; Lee, Zhongping; Hu, Chuanmin; and Wang, Menghua, "Requirement of Minimal Signal-to-noise Ratios of Ocean Color Sensors and Uncertainties of Ocean Color Products" (2017). Marine Science Faculty Publications. 1971.

https://digitalcommons.usf.edu/msc_facpub/1971

This Article is brought to you for free and open access by the College of Marine Science at Digital Commons @ University of South Florida. It has been accepted for inclusion in Marine Science Faculty Publications by an authorized administrator of Digital Commons @ University of South Florida. For more information, please contact digitalcommons@usf.edu. 


\section{Journal of Geophysical Research: Oceans}

\section{RESEARCH ARTICLE \\ 10.1002/2016JC012558 \\ Requirement of minimal signal-to-noise ratios of ocean color sensors and uncertainties of ocean color products}

Key Points:

- Minimal signal-to-noise ratio for ocean color measurements quantified for the first time

- Noise-induced uncertainties in ocean color data products also quantified at different spatial and temporal scales - Results provide support for sensor design and data interpretation in studying ocean changes in response to climate variability

Correspondence to:

L. Qi,

lin.qi@xmu.edu.cn

Citation:

Qi, L., Z. Lee, C. Hu, and M. Wang (2017), Requirement of minimal signal-to-noise ratios of ocean color sensors and uncertainties of ocean color products, J. Geophys. Res. Oceans, 122, 2595-2611, doi:10.1002/ 2016JC012558.

Received 17 NOV 2016 Accepted 1 MAR 2017 Accepted article online 7 MAR 2017 Published online 30 MAR 2017

\author{
Lin Qi' ${ }^{1}$ Zhongping Lee ${ }^{2}$ (D) Chuanmin $\mathrm{Hu}^{3}$ (D), and Menghua Wang4 \\ ${ }^{1}$ State Key Laboratory of Marine Environmental Science, Xiamen University, Xiamen, China, ${ }^{2}$ School for the Environment, \\ University of Massachusetts Boston, Boston, Massachusetts, USA, ${ }^{3}$ College of Marine Science, University of South Florida, \\ St. Petersburg, Florida, USA, ${ }^{4}$ National Oceanic and Atmospheric Administrations, Center for Satellite Applications and \\ Research, College Park, Maryland, USA
}

\begin{abstract}
Using simulations, error propagation theory, and measurements from the Moderate Resolution Imaging Spectroradiometer (MODIS), we determined the minimal signal-to-noise ratio (SNR) required for ocean color measurements and product uncertainties at different spatial and temporal scales. First, based on typical top-of-atmosphere (TOA) radiance over the ocean, we evaluate the uncertainties in satellitederived $R_{r s}$ in the visible wavelengths $\left(\Delta R_{r s}(\mathrm{vis})\right)$ due to sensor noise in both the near-infrared (NIR) and the visible bands. While the former induces noise in $R_{r s}(v i s)$ through atmospheric correction, the latter has a direct impact on $R_{r s}$ (vis). Such estimated uncertainties are compared with inherent $\Delta R_{r s}$ (vis) uncertainties from in situ measurements and from the operational atmosphere correction algorithm. The comparison leads to a conclusion that once SNR(NIR) is above 600:1, an SNR(vis) better than 400:1 will not make a significant reduction in product uncertainties at pixel level under typical conditions for a solar zenith angle of $45^{\circ}$. Then, such uncertainties are found to decrease significantly in data products of oceanic waters when the $1 \mathrm{~km}$ pixels from individual images are binned to lower spatial resolution (e.g., $4 \mathrm{~km}$ ) or temporal resolution (e.g., monthly). Although these findings do not suggest that passive ocean color sensors should have SNR(vis) around 400:1, they do support the argument for more trade space in higher spatial and/or spectral resolutions once this minimal 400:1 SNR(vis) requirement is met.
\end{abstract}

\section{Introduction}

Uncertainties in satellite ocean color data products are important parameters to define data quality, thus having direct impact on local, regional, and global studies. High uncertainties at image pixel level lead to low image quality to track ocean features or to study changes at fixed locations. High uncertainties at regional or global scale make it difficult to study ocean changes in response to climate variability because changes in the vast oceans may be very small even at decadal scale (e.g., 5-20\%) [Behrenfeld et al., 2001; Antoine et al., 2005; Gregg et al., 2005]. Thus, understanding sources of uncertainties is important in order to reduce them to improve data quality for a variety of applications. In the past, requirements on data product uncertainties at pixel level have been generally accepted by the ocean color community to be $<5 \%$ in the satellite-retrieved remote sensing reflectance $\left(R_{r s} \mathrm{sr}^{-1}\right)$ in the blue bands over clear waters and $<35 \%$ in the satellite-retrieved chlorophyll $a$ concentration $\left(\mathrm{Chl}, \mathrm{mg} \mathrm{m}^{-3}\right.$ ) also for clear waters [Hooker et al., 1992]. This is because the former is the lower boundary from atmospheric correction [Gordon, 1997], while the latter was once regarded as the uncertainties in laboratory Chl estimates. Corresponding to these requirements, uncertainties in data products have been evaluated using different approaches, including (1) direct comparison with field measurement [e.g., Gregg and Casey, 2004; McClain et al., 2004; Bailey and Werdell, 2006; Marrari et al., 2006; Mélin et al., 2007; Antoine et al., 2008; Zibordi et al., 2009; Wang et al., 2009; Maritorena et al., 2010; Cannizzaro et al., 2013; Moore et al., 2015; many others]; (2) statistics using satellite data alone [Hu et al., 2013] or cross-sensor comparisons [Zibordi et al., 2006; Barnes and Hu, 2015; Hu et al., 2013] to avoid uncertainties embedded in field measurements. These assessments have led to different findings depending on locations (i.e., open ocean or coastal water), data ranges, and methods used in the assessments.

Such uncertainties in satellite-derived data products can come from several sources, including radiometric calibration, atmospheric correction, and other correction algorithms to estimate remote sensing reflectance 


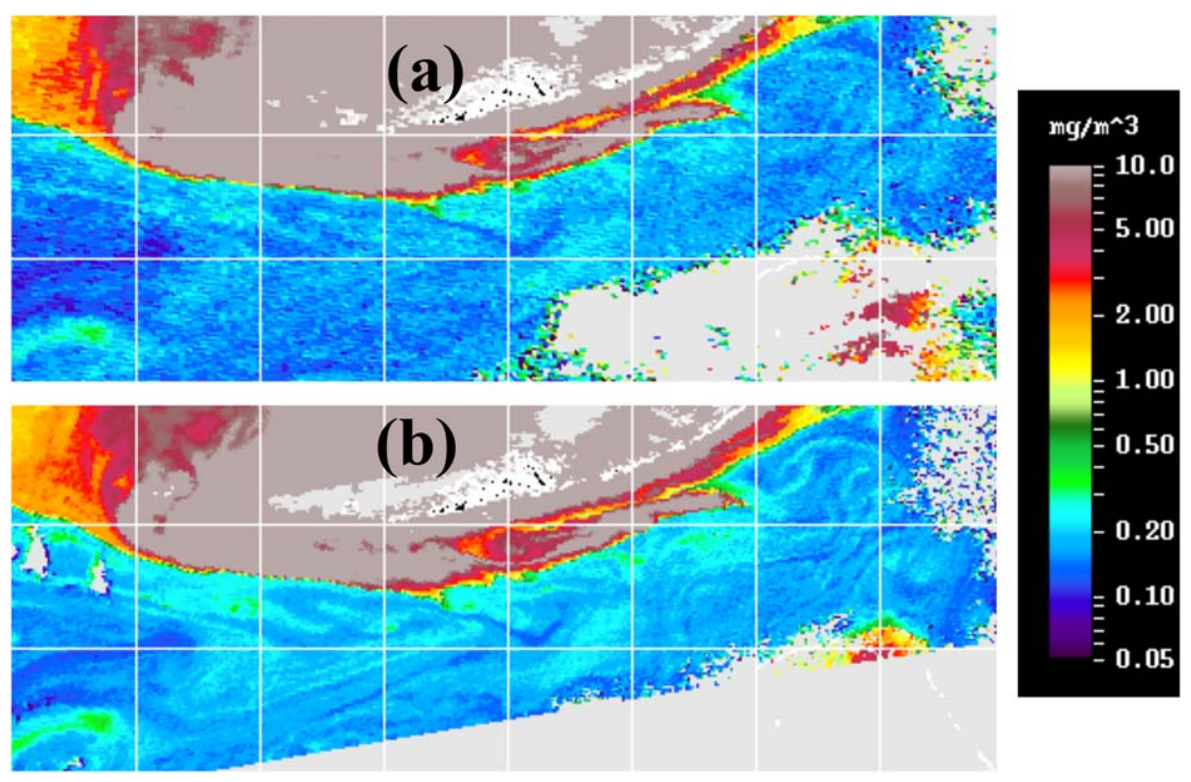

Figure 1. (a) SeaWiFS and (b) MODIS-Aqua Chl images over the Florida Straits collected on 1 December 2005. SeaWiFS shows more noise than MODIS-Aqua due to its lower SNR than MODIS [Hu et al., 2012a]. The images cover $23.5^{\circ} \mathrm{N}-25^{\circ} \mathrm{N}, 83.5^{\circ} \mathrm{W}-79.5^{\circ} \mathrm{W}$.

in the visible $\left(R_{r s}(v i s)\right)$ from at-sensor (i.e., top-of-atmosphere or TOA) total radiance, and bio-optical inversion algorithms to estimate $\mathrm{Chl}$ and other in-water properties from $R_{r s}$ (vis) [Gordon, 1990]. Additional uncertainty sources at instrument level include instrument artifact and characterization uncertainty (e.g., stray light, nearfield response, crosstalk, spectral response, linearity response, polarization response along scan direction, temperature response, detector or mirror side response), many of which can change from their prelaunch characteristics over time. However, for a well-characterized sensor where all these uncertainty sources are characterized before launch, they can all be dealt with after the satellite is launched. In contrast, another important factor affecting data product uncertainties is the sensor's signal-to-noise ratio (SNR), which must be set before the satellite is launched for obvious reason.

The question then becomes what is the minimum SNR for an ocean color sensor that can minimize spurious pixel to pixel variation, greatly improving image quality. Higher SNR leads to lower product noise, higher data precision, and lower uncertainties in data products (see Figure 1 for an example). However, increasing SNR requires trade-offs with other radiometric and spectral characteristics of the instrument [Gordon, 1990; Hu et al., 2012a]. Increasing SNR requires higher instrument sensitivity, which could lead to a lower dynamic range and lower saturation threshold (easier signal saturation over bright targets). Increasing SNR may also require coarser spatial resolution and/or lower spectral resolution in order to collect a sufficient quantity of photons. In addition, other factors contributing to data product uncertainties, as mentioned above, may overwhelm the influence of SNR once SNR is above a minimal threshold. To address the SNR requirement, Gordon [1990] obtained values of $400: 1$ to $900: 1$ at $443 \mathrm{~nm}$ for sun at $60^{\circ}$ from zenith and for scans from nadir to $45^{\circ}$ off nadir. In that study, Gordon used the uncertainty of empirically derived $\mathrm{Chl}$ as the criterion and assumed that the uncertainty from sensor's noise matched that from the blue-green ratio algorithm for the estimation of Chl. However, the key product from ocean color measurements is the $R_{r s}$ spectrum, thus it will be more informative if minimal SNR values can be obtained with $R_{r s}$ quality being used as the criterion. Indeed, a focus on the surface radiometry as a criterion for data quality has been the objective of NASA ocean color calibration and validation efforts for about two decades [McClain, 2009].

Further, nearly all previous uncertainty estimates are from the statistic of individual pixels. But in reality, most studies on regional or global processes use spatially and temporally binned data at reduced spatial resolution, for example, $4 \mathrm{~km}$ monthly means. Uncertainties in these data products are generally unknown as they have not been studied.

Therefore, the objective of this study is twofold. First, the study evaluates uncertainties in satellite-derived $R_{r s}(\mathrm{vis})$ and $\mathrm{Chl}$ as induced by sensor noise (i.e., defined by SNR) and makes recommendations on the 
minimal SNR requirement for ocean color measurements. Second, the study estimates uncertainties in $R_{r s}$ (vis) and Chl data products when the $1 \mathrm{~km}$ data products are binned to $4 \mathrm{~km}$ resolution at monthly intervals. Such estimates are based on $R_{r s}$ uncertainties estimated from sensor noise only and from realistic Moderate Resolution Imaging Spectroradiometer (MODIS) measurements over ocean gyres using error propagation theory. SNR requirements on future ocean color missions targeted for both global and regional applications are also discussed.

\section{Data and Methods}

\subsection{Definitions of Error $(\delta)$, Noise $(\sigma)$, Uncertainty $(\Delta)$, and SNR}

Several concepts need to be clarified in order to quantify uncertainties and SNR. Specifically, error $(\delta)$ is a measurement of departure from the hypothetical "truth." Sensor noise is defined as the standard deviation of a univariate Gaussian distribution of random noise errors, denoted as $\sigma$ in units of $\mathrm{mW} \mathrm{cm}{ }^{-2} \mu \mathrm{m}^{-1} \mathrm{sr}^{-1}$, which is a scalar from error statistics (i.e., many $\delta$ values). Uncertainty is also a scalar, $\Delta$, defined as the probability of a measured (or estimated) property in approaching the hypothetical "truth." The sample standard deviation of the error distribution from many $(\mathrm{N})$ measurements is regarded as the measurement uncertainty $(\Delta)$. Another way to interpret $\Delta$ is that, from a single measurement, the measured value has a $68 \%$ likelihood to have its error $<\Delta$. In this regard, sensor noise is also the uncertainty in the sensor signal. Most importantly, uncertainty $(\Delta)$ is not an error but a measure of error distribution and probability.

Note that there are three notations used here: $\delta, \sigma$, and $\Delta$, which have specific meanings in this context. They are all used as operators, such that $\delta \mathrm{X}$ is the error in $\mathrm{X}$, and $\sigma \mathrm{X}$ is the standard deviation of the error distribution in $\mathrm{X} . \Delta \mathrm{X}$ has the same meaning of $\sigma \mathrm{X}$, but in this context $\sigma$ is reserved for sensor signal (radiance) but $\Delta$ is reserved for data products (e.g., $R_{\mathrm{rs}}, \mathrm{Chl}$ ).

SNR is defined as the ratio of signal versus noise $(\sigma)$. For an input radiance $\left(L, \mathrm{~mW} \mathrm{~cm}{ }^{-2} \mu \mathrm{m}^{-1} \mathrm{sr}^{-1}\right)$ and $\sigma$, we have

$$
\mathrm{SNR}=L / \sigma .
$$

One objective of this study is to determine a minimal SNR with $L$ from typical measurements over the ocean $\left(L=L_{\text {typ }}\right)$ [Hu et al., 2012a].

\subsection{Determination of Minimal SNR}

As stated above, for a spectral band in the visible, total uncertainties in $R_{r s}(v i s)$ from satellite retrievals, $\Delta R_{r s}{ }^{\text {total }}$ (vis), come from four sources: (1) radiometric calibration, (2) atmospheric correction, (3) sensor noise $(\sigma)$, and (4) sensor artifacts and characterization uncertainty (e.g., stray light, near-field response, crosstalk, spectral response, linearity response, polarization response along scan direction, temperature response, detector or mirror side response) as well as uncertainties in ancillary data (e.g., wind, ozone, atmospheric pressure, water vapor) used during atmospheric correction. Incorrect radiometric calibration will not contribute to sensor noise but instead lead to a systematic bias (offset) in the satellite-derived $R_{r s}$ although such a bias may vary with solar/viewing geometry and other measurement conditions. Because the focus of this study is on noise-induced $\Delta R_{r s}{ }^{\text {total }}$ (vis), radiometric calibration will not be discussed, but \#2 and \#3 factors will be the focus here. The \#2 factor is considered here because in addition to $\sigma$ (vis)-induced uncertainty in $\Delta R_{r s}{ }^{\text {total }}$ (vis), $\sigma(\mathrm{NIR})$ will also contribute to $\Delta R_{r s}{ }^{\text {total }}$ (vis) through the atmospheric correction process as the near-infrared (NIR) bands are used in the atmospheric correction. The \#4 factor may play an important role in affecting atmospheric correction accuracy, but it is from sources other than sensor noise, hence not considered here.

Therefore, in order to determine the minimal SNR, two questions need to be addressed: (1) what is the current "state-of-the-art" $\Delta R_{r s}{ }^{\text {total }}$ (vis), as estimated from simulations and measurements? and (2) what is the minimal SNR that can meet the requirement of such "state-of-the-art" $\Delta R_{r s}{ }^{\text {total }}$ (vis)?

Ignoring the impact of sensor's calibration, the two independent terms contributing to $\Delta R_{r s}{ }^{\text {total }}$ (vis) are $\Delta R_{r s}{ }^{\text {atm }}$ (vis) and $\Delta R_{r s}{ }^{\sigma}$ (vis), where the former is induced by the standard atmospheric correction procedure [Gordon and Wang, 1994; Wang, 2007] that was recently updated in Wang et al. [2012], and the latter is a result of sensor noise $\sigma$ (vis). 
For independent noise terms and following the theory of statistics and probability [Morgan and Henrion, 1990], $\Delta R_{r s}^{\text {total }}$ (vis) from these two terms can be calculated as

$$
\Delta R_{r s}{ }^{\text {total }}(\text { vis })=\sqrt{\left(\Delta R_{r s}{ }^{a t m}(\text { vis })\right)^{2}+\left(\Delta R_{r s}{ }^{\sigma}(v i s)\right)^{2}} .
$$

Wang et al. [2012] have demonstrated that with the current atmosphere correction procedure that is based on the original Gordon and Wang [1994] scheme with recent updates in aerosol lookup tables (LUTs), $\Delta R_{r s}{ }^{a t m}$ (vis) will approach a theoretical limit and will be reduced only marginally with further increased SNR(NIR) after it reached a certain threshold, and this threshold was determined to be 600:1. SNR(NIR) was therefore set to 600:1 in this study, as this number can be regarded as "enough" for the NIR bands.

However, it is difficult to answer the question on how much SNR(vis) is "enough," as the answer will depend completely on the oceanographic applications. For certain applications, an SNR(vis) may be "enough" but for other applications the same SNR(vis) may be far from "enough," and in the end for some applications even an SNR(vis) of infinity may still not be "enough" because $\Delta R_{r s}{ }^{\text {total }}$ (vis) in this case will approach $\Delta R_{r s}{ }^{\text {atm }}$ (vis). Therefore, question \#2 from the above is rephrased as follows: what is the minimal SNR(vis) required for observing common situations of oceanic waters, above which the gain in reduced satelliteretrieved $\Delta R_{r s}{ }^{\text {total }}$ (vis) is not as dramatic as when SNR(vis) is below such a minimal SNR(vis)? Because once $\Delta R_{r s}{ }^{\text {atm }}$ (vis) is fixed (under SNR(NIR) $\left.=600: 1\right), \Delta R_{r s}{ }^{\text {total }}$ (vis) is a monotonic function of $\Delta R_{r s}{ }^{\sigma}$ (vis). $\Delta R_{r s}{ }^{\sigma}$ (vis) can therefore be used as the metric to determine minimal SNR(vis). Specifically, two criteria were used, which led to two different specifications of SNR(vis). One criterion is to use the best $\Delta R_{r s}{ }^{\text {field }}$ (vis) to bound the $\mathrm{SNR}$ (vis) determination, and another is to use $\Delta R_{r s}{ }^{\text {atm }}$ (vis) (from atmospheric correction) to bound the $\mathrm{SNR}$ (vis) determination. In such calculations, we have

$$
\sigma(\text { vis })=L_{\text {typ }}(\text { vis }) / S N R(\text { vis })
$$

resulting in

$$
\Delta R_{r s}{ }^{\sigma}(v i s)=\frac{\sigma(v i s)}{t(v i s) \cdot\left[F_{0}(v i s) \cos \theta_{0} t_{0}(v i s)\right]},
$$

where $F_{0}$ is the extraterrestrial solar irradiance, $\theta_{0}$ is the solar zenith angle, $t_{0}$ is the atmospheric diffuse transmittance from the sun to the sea surface, and $t$ is the atmospheric diffuse transmittance from the sea surface to the sensor. $\left[F_{0}(v i s) \cos \left(\theta_{0}\right) t_{0}(v i s)\right]$ in the above equation is the sea surface downwelling irradiance.

In short, we can define SNR(vis) thresholds using the SNR required to achieve the quality of the best field measurement, represented by $\Delta R_{r s}{ }^{\text {field }}$ (vis), and the SNR required to achieve the uncertainty level comparable to the uncertainty inherent to the atmospheric correction algorithm, $\Delta R_{r s}{ }^{\text {atm }}$ (vis). These two thresholds, namely $\mathrm{SNR}_{1}$ and $\mathrm{SNR}_{2}$, respectively, can be written as

$$
S N R_{1}(\text { vis })=\frac{L_{\text {typ }}(\text { vis })}{t(\text { vis }) \cdot R_{r s}{ }^{\text {field }}(\text { vis }) \cdot\left[F_{0}(\text { vis }) \cos \left(\theta_{0}\right) t_{0}(v i s)\right]}
$$

and

$$
S N R_{2}(\text { vis })=\frac{L_{t y p}(\text { vis })}{t(\text { vis }) \cdot R_{r s}{ }^{a t m}(v i s) \cdot\left[F_{0}(v i s) \cos \left(\theta_{0}\right) t_{0}(v i s)\right]} .
$$

\subsection{Uncertainties in Chl Data Product}

Of all the ocean color products, $\mathrm{Chl}$ perhaps is the most often used. Because $\mathrm{Chl}$ is derived from spectral $R_{r s t}$ $\Delta R_{r s}$ (vis) will lead to $\Delta \mathrm{Chl}$ through error propagation. The current NASA standard Chl algorithm of MODIS is based on OCI [Hu et al., 2012b], which is a mixture of $R_{r s}$ three-band subtraction (color index or $\mathrm{Cl}$ ) and $R_{r s}$ ratio among three bands $\left(\mathrm{OC}_{3 \mathrm{~m}}\right)$. In addition to MODIS, NASA has applied this algorithm to all ocean color sensors including the Visible Infrared Imaging Radiometer Suite (VIIRS), Sea-viewing Wide Field-of-view Sensor (SeaWiFS), Coastal Zone Color Scanner (CZCS), and Medium-Resolution Imaging Spectrometer (MERIS). The NOAA ocean color team has also implemented the $\mathrm{OCl}$ algorithm for the ocean color data processing from the VIIRS [Wang and Son, 2016]. Here we will briefly explain how $\Delta R_{r s}$ propagates to $\Delta C h l$. As stated earlier, both $\Delta R_{r s}$ and $\Delta \mathrm{Chl}$ represent standard deviations of error distributions. 
The OC $_{3 m}$ algorithm [O'Reilly et al., 1998] takes the following form:

$$
\begin{gathered}
C h l_{O C 3}=10^{y}, \\
y=a_{0}+a_{1} \chi+a_{2} \chi^{2}+a_{3} \chi^{3}+a_{4} \chi^{4}, \\
\chi=\log _{10}(R) \text { and } R=\max \left(R_{r s}(443), R_{r s}(448)\right) / R_{r s}(547),
\end{gathered}
$$

where $a_{0}-a_{4}$ are the empirical regression coefficients of $0.2424,-2.7423,1.8017,0.0015$, and -1.2280 , respectively.

According to error propagation theory between independent variables and dependent variables, we have

$$
\begin{gathered}
\Delta C h l_{O C 3}=\frac{d\left(C h l_{O C 3}\right)}{d y} \cdot \Delta y=10^{y} \cdot \ln 10 \cdot \Delta y=C h l_{O C 3} \cdot \ln 10 \cdot \Delta y, \\
\Delta y=\frac{d y}{d \chi} \cdot \Delta \chi=\left(a_{1}+2 a_{2} \chi^{1}+3 a_{3} \chi^{2}+4 a_{4} \chi^{3}\right) \cdot \Delta \chi \\
\Delta \chi=\frac{d \chi}{d R} \cdot \Delta R=\frac{1}{R \cdot \ln 10} \cdot \Delta R .
\end{gathered}
$$

The difficulty is how to estimate $\Delta \mathrm{R}$ from $\Delta R_{r s}^{\text {total }}$ (vis) of the individual bands. For simplicity, assuming $R=R_{1} / R_{2}$ where $R_{1}$ is the numerator in equation (9) and $R_{2}$ is the denominator in equation (9), then if errors in $R_{1}$ and $R_{2}$ are independent, error propagation theory will lead to

$$
\Delta R=\sqrt{\left(\frac{\partial R}{\partial R_{1}} \Delta R_{1}\right)^{2}+\left(\frac{\partial R}{\partial R_{2}} \Delta R_{2}\right)^{2}} .
$$

IOCCG [2010] and Hu et al. [2013] showed that $\Delta R_{r s}{ }^{\text {total }}$ (vis) is not spectrally independent. Here we generated the same error statistics based on Hu et al. [2013] and then calculated $\Delta \mathrm{R}$. First, 5000 random errors of $R_{r s}(\delta$, $\left.\mathrm{sr}^{-1}\right)$ were generated for each of the three bands $(443,547$, and $667 \mathrm{~nm})$, and these errors were generated in a way to agree with the MODIS $R_{r s}$ error statistics given in Hu et al. [2013, Figure10]. There is a spectral relationship (i.e., dependence) among the different bands to account for errors due to atmospheric correction, while there is also a certain degree of randomness (i.e., independence) among different bands due to instrument noise (SNR(vis)). Further, we have

$$
\delta R=\frac{R_{1}+\delta R_{1}}{R_{2}+\delta R_{2}}-\frac{R_{1}}{R_{2}} .
$$

Here $\delta R$ is not just a function of $\delta R_{1}$ and $\delta R_{2}$, but also a function of $R_{1}$ and $R_{2}$, which further depend on Chl. In this study, $R_{1}$ and $R_{2}$ were selected to represent most oceanic waters with Chl ranging between 0.04 and $10.00 \mathrm{mg} \mathrm{m}^{-3}$. While in reality the same Chl may correspond to different $R_{1}$ or $R_{2}$ (and vice versa), for illustration purpose in this study $\mathrm{Chl}$ was equally spaced (in log scale) between 0.04 and $10.00 \mathrm{mg} \mathrm{m}^{-3}$, and for each predefined $\mathrm{Chl}$ in this range its corresponding $R_{r s}(\mathrm{vis})$ (and therefore $R_{1}$ and $R_{2}$ ) was determined as the median spectrum from MODIS global $R_{r s}$ statistics.

The $5000 \delta \mathrm{R}$ values estimated this way will form an error distribution, and its standard deviation is regarded as $\Delta \mathrm{R}$. Once $\Delta \mathrm{R}$ is derived, $\Delta \mathrm{Chl}_{\mathrm{OC} 3}$ is derived through equations (10-12).

The $\mathrm{Cl}$ algorithm takes the following form:

$$
\begin{gathered}
C h l_{C l}=10^{y}, \\
y=a_{0}+a_{1} \cdot C l,
\end{gathered}
$$

where $a_{0}$ and $a_{1}$ are algorithm coefficients (constants) and

$$
\begin{gathered}
C l=R_{r s}(547)-\left[R_{r s}(443)+(547-443) /(667-443) \times\left(R_{r s}(667)-R_{r s}(443)\right)\right], \\
C l \approx R_{r s}(547)-0.5\left(R_{r s}(443)+R_{r s}(667)\right)
\end{gathered}
$$

Then, for each of the $5000 \delta R_{r s}$ of the three bands, we have 


$$
\begin{gathered}
\delta C l=\left(R_{2}+\delta R_{2}\right)-0.5\left(\left(R_{1}+\delta R_{1}\right)+\left(R_{3}+\delta R_{3}\right)\right)-\left(R_{2}-0.5\left(R_{1}+R_{3}\right)\right) \\
=\delta R_{2}-0.5\left(\delta R_{1}+\delta R_{3}\right)
\end{gathered}
$$

Here $R_{1}, R_{2}$, and $R_{3}$ represent $R_{r s}(443), R_{\mathrm{rs}}(547)$, and $R_{\mathrm{rs}}(667)$, respectively.

The standard deviation of the $5000 \delta \mathrm{Cl}$ is $\Delta \mathrm{Cl}$. Subsequently, we have

$$
\Delta C h l_{C l}=10^{y} \cdot \ln 10 \cdot \Delta y,
$$

where

$$
\Delta y=\frac{d y}{d C l} \cdot \Delta C l=a_{1} \cdot \Delta C l
$$

The current NASA standard $\mathrm{OCl}$ algorithm is a mixture between $\mathrm{Cl}$ and $\mathrm{OC}_{3 \mathrm{~m}}$ :

$$
\begin{gathered}
C h l_{O C I}=C h l_{C I}\left[\text { for } C h l_{C I} \leq 0.175 \mathrm{mg} \mathrm{m}^{-3}\right], \\
=C h l_{O C 3}\left[\text { for } C h l_{C I}>0.25 \mathrm{mg} \mathrm{m}^{-3}\right], \\
=\alpha \times C h l_{O C 3}+\beta \times C h l_{C I}\left[\text { for } 0.175<C h l_{C I} \leq 0.25 \mathrm{mg} \mathrm{m}^{-3}\right],
\end{gathered}
$$

where

Finally, we have

$$
\alpha=\frac{C h l_{C l}-0.175}{0.25-0.175}, \quad \beta=\frac{0.25-C h l_{C l}}{0.25-0.175}
$$

$$
\Delta C h l_{O C I}=\sqrt{\alpha^{2} \Delta C h l_{O C 3}^{2}+\beta^{2} \Delta C h l_{C I}^{2}}
$$

where $\Delta \mathrm{Chl}_{\mathrm{OC} 3}$ and $\Delta \mathrm{Chl}_{\mathrm{Cl}}$ are derived from equation (10) and equation (19), respectively.

\subsection{Data Product Uncertainties After Data Binning}

$\Delta R_{r s}{ }^{\text {total }}$ (vis) and $\Delta \mathrm{Chl}$ ocl derived above were presented as the statistics of error distribution from individual pixels. As stated earlier, for repeated measurements, they indicated the standard deviation of error distribution. For a single measurement, they indicate the probability (68\%) of the measurement error within $\Delta R_{r s}{ }^{\text {total }}$ (vis) and $\Delta \mathrm{Chl}_{\mathrm{OCl}}$.

In practice, data from individual images at its original spatial resolution (e.g., $1 \mathrm{~km}$ for MODIS or $750 \mathrm{~m}$ for VIIRS) were rarely used for regional or global studies of ocean science due to significant cloud cover or other nonoptimal measurement conditions [Feng and $\mathrm{Hu}, 2016$ ]. Instead, these data of original spatial resolution were often binned to coarser spatial resolutions in 8 day, monthly, seasonal, or annual composites, projected into a plate carrée grid. These composites help reduce cloud cover and increase coverage, resulting in $\mathrm{N}$ valid measurements for each grid cell. According to error statistics and assuming that each measurement error in either $R_{r s}$ or $\mathrm{Chl}$ is independent of others, uncertainty for each grid cell will reduce by $1 / \mathrm{sqrt}(\mathrm{N})$ :

$$
\sigma=\sigma_{0} / \sqrt{N}
$$

Here as an example the number of $\mathrm{N}$ for each grid cell was determined from MODIS global measurements. MODIS L3 $4 \mathrm{~km}$ binned monthly $R_{r s}$ data products were obtained from NASA. In such products, for each grid cell, all valid $1 \mathrm{~km}$ pixels that fall in the grid cell within the given month were used to calculate the mean $R_{r s}$ while the number of valid pixels in the calculation was also recorded. For illustration purpose, the month of June 2008 (north hemisphere summer) was selected. For the $\mathrm{i}^{\text {th }}$ grid cell uncertainties were estimated as

$$
\Delta R_{r s}{ }^{\text {total }}(\operatorname{vis}) /\left(\operatorname{sqrt}\left(\mathrm{N}_{\mathrm{i}}\right)\right) \text { and } \Delta \mathrm{Chl}_{\mathrm{OCl}} /\left(\operatorname{sqrt}\left(\mathrm{N}_{\mathrm{i}}\right)\right) \text {, }
$$

where $\Delta R_{r s}{ }^{\text {total }}$ (vis) and $\Delta \mathrm{Chl}$ ocl were from the estimates in section 2.3.

\section{Results}

\subsection{Minimal SNRs}

One of the best (i.e., minimal) $\Delta R_{r s}$ (vis) from field measurements, $\Delta R_{r s}$ (vis) ${ }^{\text {field }}$, was from the skylight-blocked approach (SBA) measurements [Lee et al., 2013] taken in blue oceanic waters, as shown in Figure 2. The SBA 


\section{QAGU Journal of Geophysical Research: Oceans}

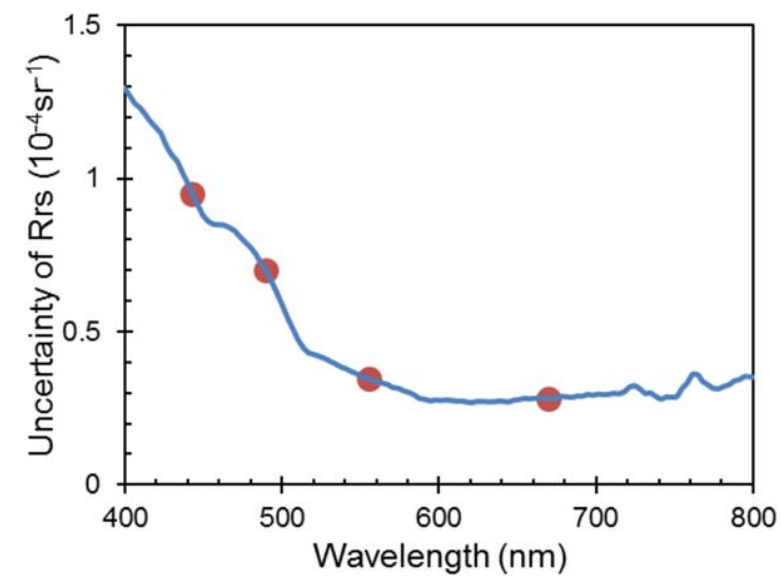

Figure 2. $\Delta R_{r s}^{\text {field }}$ from the best SBA measurements of Lee et al. [2013]. This represents minimal $R_{r s}$ uncertainties from any field measurements. values were used to represent one of the two criteria to determine minimum SNR(vis), i.e., $\mathrm{SNR}_{1}$. Four spectral bands are annotated $(443,488,547,667 \mathrm{~nm})$, whose $\Delta R_{r s}$ field

measurement scheme is similar to a typical above-water reflectance measurement except that a custom-made cone is used to block surface-reflected skylight, therefore minimizing potential errors from incorrect removal of reflected skylight. The highest-quality reflectance data collected by marine buoys designed specifically for measuring reflectance typically had 3-4\% of uncertainties in the blue bands for blue waters [Antoine et al., 2008], while the uncertainties due to noise in the best SBA measurements over blue waters are only $\sim 1 \%\left(0.0001 \mathrm{sr}^{-1}\right.$ divided by a typical blue-water $R_{r s}$ at $443 \mathrm{~nm}, 0.01 \mathrm{sr}^{-1}$, Figure 2). Therefore, these $\Delta R_{r s}^{\text {field }}$ (vis) represent the minimal uncertainties that can be achieved by today's state-of-the-art measurements, which is then used to bound $\mathrm{SNR}_{1}$ calculations in equation (5).

$\Delta R_{r s}$ (vis) from atmospheric correction, $\Delta R_{r s}{ }^{a t m}$ (vis), for the four visible bands $(443,488,547,667 \mathrm{~nm})$ are shown in Figure 3 . These were used as the bound to calculate $\mathrm{SNR}_{2}$ through equation (6). While different aerosol types and thicknesses led to different
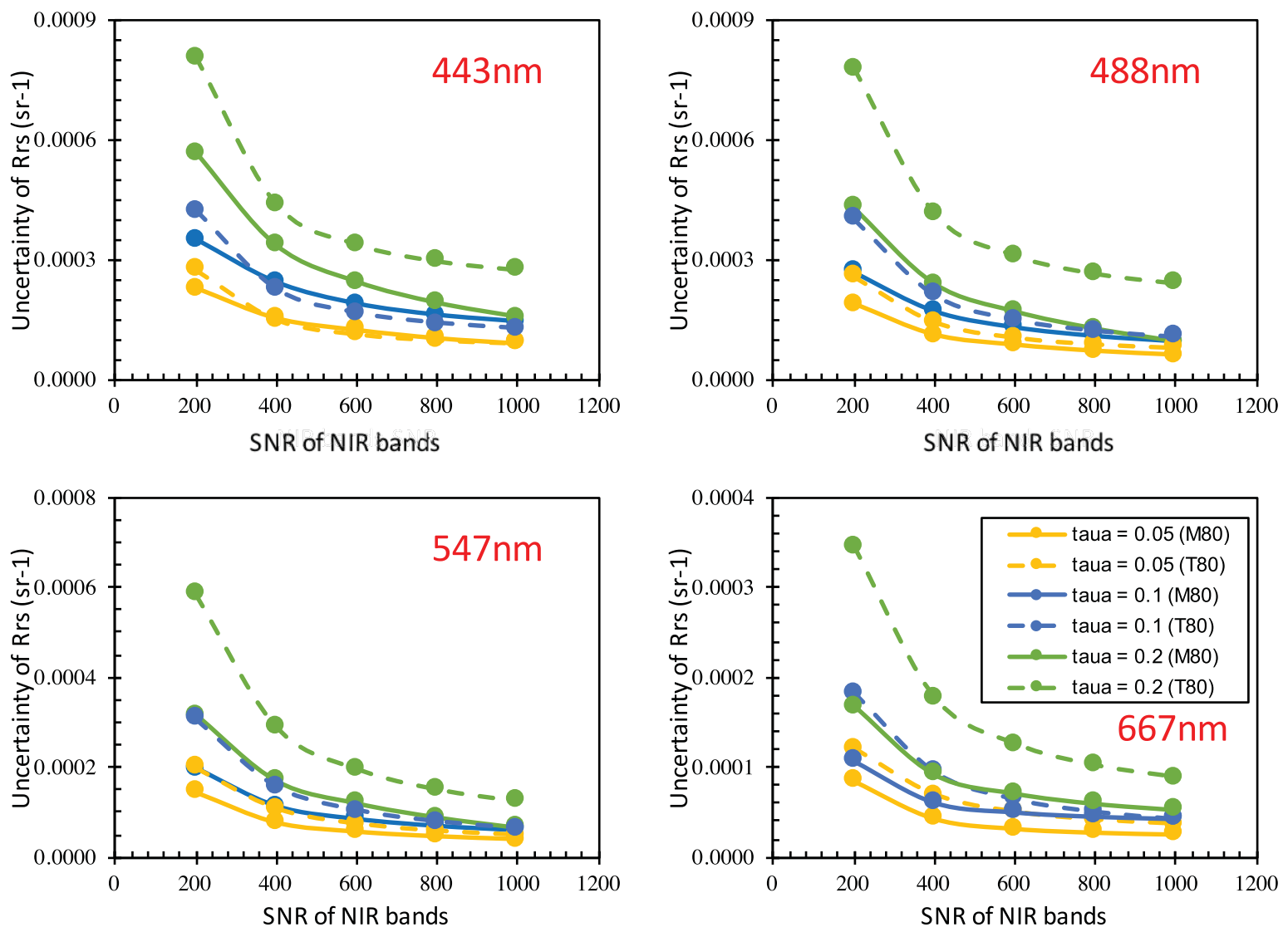

Figure 3. $\Delta R_{r s}{ }^{a t m}$ in the visible bands induced by atmospheric correction under different scenarios (aerosol type and optical thickness). M80 represents maritime aerosol with $80 \%$ relative humidity, and T80 represents tropospheric aerosol with $80 \%$ relative humidity. Aerosol optical thickness $\left(\tau_{\mathrm{a}}\right)$ is expressed in "taua." For the global ocean, M 80 with taua $=0.1$ is the typical case. 


\section{QAGU Journal of Geophysical Research: Oceans}
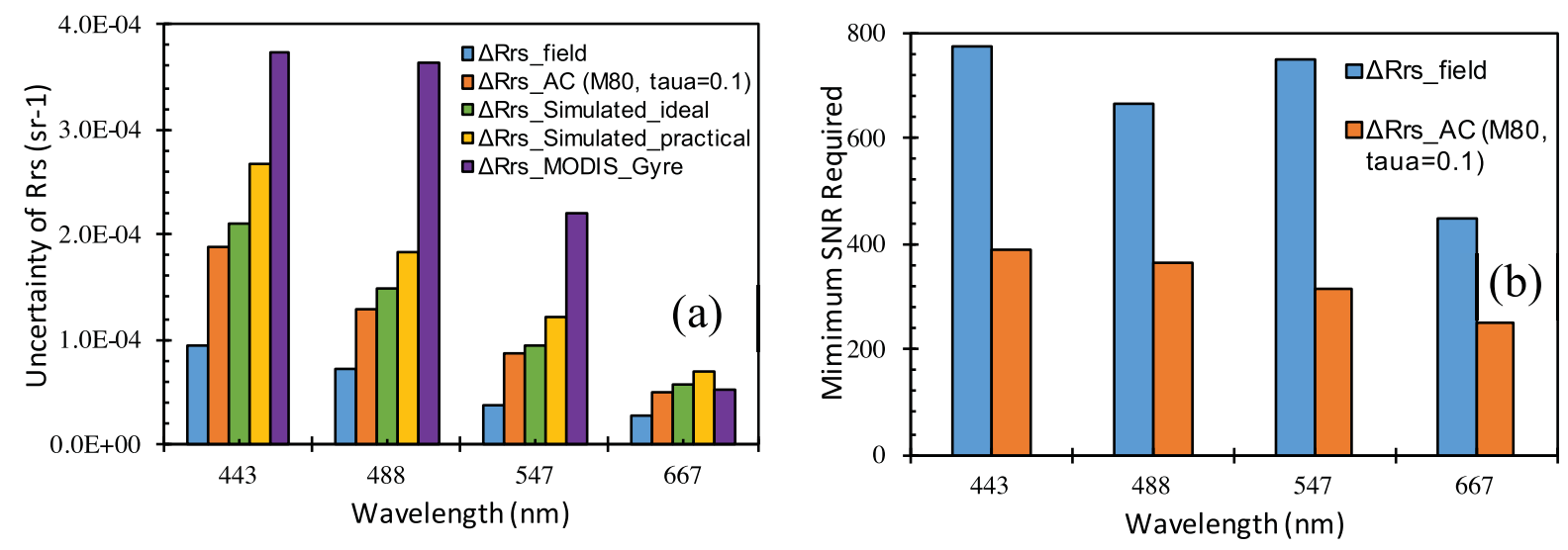

Figure 4. (a) The five $\Delta R_{r s}$ terms for each of the four visible bands: $\Delta R_{r s}$ field is from the best field measurement (Figure 2); $\Delta R_{r s}$ atm is from atmospheric correction over typical global oceans; $\Delta R_{r s}\left(\right.$ simulated_ideal) is the combined uncertainty from equations (2) and (5), and $\Delta R_{r s}$ (simulated_practical) is the combined uncertainty from equations (2) and (6); $\Delta R_{r s}(\mathrm{MODIS}$ Gyre) is $\Delta R_{r s}{ }^{\text {gyre }}$. (b) Minimal SNR determined from equation (5) $\left(S N R_{1}\right)$ and equation (6) $\left(S N R_{2}\right)$, i.e., when $\Delta R_{r s}{ }^{\text {field }}$ and $\Delta R_{r s}{ }^{\text {atm }}$ in Figure 4 a were used to bound the $\Delta R_{r s}{ }^{\sigma}$ term.

$\Delta R_{r s}{ }^{\text {atm }}$ (vis), according to MODIS statistics most global oceans have M80 aerosols with $\tau_{\mathrm{a}}=0.1$ in the NIR band, the results from this scenario were used as $\Delta R_{r s}{ }^{\text {atm }}$ (vis) to estimate $S_{N R}$.

Figure 4 a shows the five $\Delta R_{r s}$ terms for each of the four visible bands. Of these, $\Delta R_{r s}$ field is the lowest $\left(<10^{-4}\right.$ $\mathrm{sr}^{-1}$ for all bands), representing the state-of-the-art $R_{r s}$ uncertainty from any field measurements. Corresponding to $\Delta R_{r s}$ field, $\mathrm{SNR}_{1}$ was determined from equation (5) under the assumption of typical radiance input with a solar zenith angle of $45^{\circ}$, with results shown in Figure $4 \mathrm{~b}$ (blue bars). Note that even for such a requirement to make $\Delta R_{r s}{ }^{\sigma}$ equal to $\Delta R_{r s}$ field, $\mathrm{SNR}_{1}$ of $800: 1$ is sufficient for all visible bands.

$\Delta R_{r s}{ }^{\text {atm }}$ is much higher than $\Delta R_{r s}{ }^{\text {field }}$ for all bands (Figure 4a). Corresponding to $\Delta R_{r s}{ }^{\text {atm }}$, SNR 2 was determined from equation (6), with results shown in Figure $4 \mathrm{~b}$ (orange bars). Note that $\mathrm{SNR}_{2}$ is $<400: 1$ for all visible bands, much lower than $\mathrm{SNR}_{1}$. This suggests that if one were to make $\Delta R_{r s}{ }^{\sigma}$ comparable to $\Delta R_{r s}{ }^{\text {atm }}, \mathrm{SNR}$ could be lower than 1000:1, a number that was recommended by the IOCCG [2012] report.

Corresponding to $S N R_{1}$ and $S N R_{2}, \Delta R_{r s}^{\text {total }}$ derived from equation (2) are shown in Figure 4 a as green and yellow bars, respectively, and annotated as $\Delta R_{r s}{ }^{\text {ideal }}$ and $\Delta R_{r s}{ }^{\text {practical }}$, respectively. $\Delta R_{r s}$ ideal is slightly higher than $\Delta R_{r s}{ }^{\text {atm }}$, and $\Delta R_{r s}{ }^{\text {practical }}$ is 1.41 times $\Delta R_{r s}{ }^{\text {atm }}$, both indicating the dominant role of $\Delta R_{r s}{ }^{\text {atm }}$ in determining $\Delta R_{r s}{ }^{\text {total }}$. This observation is consistent with those from image statistics [Hu et al., 2012a] where improving SNR(vis) has been shown far less important than improving SNR(NIR) in terms of reducing data product noise and uncertainties in the visible domain.

From this analysis, one can conclude that once SNR(NIR) is $>600: 1$ and the Gordon and Wang [1994] approach is used for atmospheric correction, SNR(vis) can be 800:1 or even 400:1 without sacrificing image quality in terms of noise and uncertainty. This finding is actually consistent with those reported in Gordon [1990] for Chl retrieval and $\mathrm{Hu}$ et al. [2012c] where comparison was made between Geostationary Ocean Color Imager (GOCI), SeaWiFS, and MODIS (see Table 1 and Hu et al. [2012c, Figures 1 and 2]). Although GOCI SNR(vis) is much lower ( 600:1) than MODIS SNR(vis) (>2000:1) and GOCI SNR(NIR) is also lower ( 600:1) than MODIS SNR(NIR) (800:1 at $869 \mathrm{~nm}$ and 1000:1 at $754 \mathrm{~nm}$ ), because GOCI SNR(NIR) is approaching 600:1, the noise levels in their band-ratio $\mathrm{Chl}$ products are similar [Hu et al., 2012c, Figures 1 and 2]. For the same reason, because SeaWiFS SNR(NIR) is much lower ( 200:1) than GOCI SNR(NIR) ( 600:1), even if the SNR(vis) of both sensors is very similar, the noise level in SeaWiFS band-ratio Chl is much higher than that in $\mathrm{GOCl}$ band-ratio $\mathrm{Chl}$.

Therefore, without examining details of all possible scenarios, the results in Figure 4 and from the above analyses suggest that even for the "ideal" requirement where $\Delta R_{r s}{ }^{\sigma}$ is forced to agree with $\Delta R_{r s}$ field, a SNR(vis) of 800:1 is sufficient. For the "practical" requirement where $\Delta R_{r s}{ }^{\sigma}$ is forced to agree with $\Delta R_{r s}{ }^{\text {atm }}$, a SNR(vis) of 400:1 is sufficient. Both SNR(vis) choices led to $\Delta R_{r s}^{\text {total }}$ lower than MODIS $\Delta R_{r s}$ gyre (Figure $4 a$, purple bars). 


\section{CAGU Journal of Geophysical Research: Oceans}

\subsection{Product Uncertainties Due to Sensor Noise}

Once $\Delta R_{r s}{ }^{\text {total }}$ at pixel level is determined for each spectral band, it is straightforward to calculate $\Delta R_{r s}$ and $\Delta \mathrm{Chl}$ for each $4 \mathrm{~km}$ grid cell in the monthly data products using the $1 / \mathrm{sqrt}(\mathrm{N})$ rule where $\mathrm{N}$ is the number of valid observations in each grid cell. Figure 5 shows the \# of valid pixels in each $4 \mathrm{~km}$ grid cell in June 2008 . Note the uneven distributions in the global oceans, for example, the low values in the equatorial regions and in the Indian Ocean due to persistent cloud cover, sun glint, and stray light.

In this study, three forms of $\Delta R_{r s}{ }^{\text {total }}$ at pixel level were used: $\Delta R_{r s}{ }^{\text {ideal }}, \Delta R_{r s}{ }^{\text {practical }}$, and $\Delta R_{r s}{ }^{\text {gyre }}$ in Figure $4 \mathrm{a}$, respectively. $\Delta R_{r s}{ }^{\text {ideal }}$ is the minimal uncertainty an ocean color sensor can achieve (corresponding to SNR(vis) of $\sim 800: 1$ and SNR(NIR) of $\sim 600: 1) ; \Delta R_{r s}{ }^{\text {practical }}$ is the most cost effective way to design a sensor (corresponding to SNR(vis) of $\sim 400: 1$ and SNR(NIR) of $\sim 600: 1$ ); $\Delta R_{r s}{ }^{\text {gyre }}$ represents the best performance of the current ocean color sensors.

Figure 6 shows $\Delta R_{r s}$ in each $4 \mathrm{~km}$ grid cell for June 2008, corresponding to the three $\Delta R_{r s}^{\text {total }}$ at pixel level. Figure 7 shows the same $\Delta R_{r s}$ in each $4 \mathrm{~km}$ grid cell for June 2008 but in relative units (relative to the monthly mean $R_{r s}$ ). For all but the $667 \mathrm{~nm}$ visible bands, nearly all grid cells showed $<5 \%$ uncertainties regardless of the assumptions used at pixel level, suggesting that at $4 \mathrm{~km}$ monthly scale, ocean color mission goals of obtaining $R_{r s}$ with $<5 \%$ uncertainties can be met for nearly all waters instead of just blue waters. This is attributed to the $\mathrm{N}>1$ valid observation in nearly all $4 \mathrm{~km}$ grid cells at monthly scale.

$\Delta R_{r s}{ }^{\text {total }}$ at pixel level would propagate to $\Delta \mathrm{Chl}$ at pixel level through equations (10-23), where $R_{r s}$ errors in different bands (equation (14)) are shown in Figure 8 according to MODIS statistics over ocean gyres [Hu et al., 2013]. These errors would add on top of the $R_{r s}$ spectra corresponding to different Chl levels (Figure 9a) to result in $\mathrm{Chl}$ errors and $\mathrm{Chl}$ uncertainties (i.e., $\Delta \mathrm{Chl}$ ). Such $\Delta \mathrm{Chl}$ for the three $\Delta R_{r s}{ }^{\text {total }}$ cases (i.e., $\Delta R_{r s}{ }^{\text {ideal }}, \Delta R_{r s}{ }^{\text {practical }}$, and $\Delta R_{r s}{ }^{\text {gyre }}$ ) are shown in Figures $9 \mathrm{~b}-9 \mathrm{~d}$, respectively. For the $\mathrm{OC}_{\mathrm{X}}$ algorithm, $\Delta \mathrm{Chl}$ is high for both clear $\left(\mathrm{Chl}<0.1 \mathrm{mg} \mathrm{m}^{-3}\right)$ and turbid $\left(\mathrm{Chl}>0.5 \mathrm{mg} \mathrm{m}^{-3}\right)$ waters, with the turning point around $\mathrm{Chl} \sim 0.2 \mathrm{mg} \mathrm{m}^{-3}$. This is understandable because for $\mathrm{Chl}<0.1 \mathrm{mg} \mathrm{m}^{-3}$, the reflectance ratio (R) is $\gg 1$ but for $\mathrm{Chl}>0.5 \mathrm{mg} \mathrm{m}^{-3}$ the ratio is $\ll 1$. In contrast, $\Delta \mathrm{Chl}$ from the $\mathrm{OCl}$ algorithm is much lower and is nearly a constant $(<5 \%)$ for $\mathrm{Chl}<0.25 \mathrm{mg} \mathrm{m}^{-3}$ because most of the $R_{r s}$ errors in the three algorithm bands cancelled [Hu et al., 2012b]. This is exactly what the algorithm was designed for.

Similar to the reduction of $\Delta R_{r s}$ when applied to monthly $4 \mathrm{~km}$ data, $\Delta \mathrm{Chl}$ at pixel level (Figure 9) also decreased significantly when applied to monthly $4 \mathrm{~km}$ data (Figure 10). For illustration purpose, only $\Delta \mathrm{Chl}$ at pixel level in Figure 9d was applied to June 2008 to show the global distributions of $\Delta \mathrm{Chl}$ in Figure 10. Most of the $\mathrm{OC}_{\mathrm{x}} \Delta \mathrm{Chl}$ values are $<5 \%$, with some of them between $5 \%$ and $10 \%$ over some of the ocean gyres where $\mathrm{Chl}$ is extremely low $\left(<0.07 \mathrm{mg} \mathrm{m}^{-3}\right)$ and number of valid observations is also low. In contrast, nearly all $\mathrm{OCl} \Delta \mathrm{Chl}$ values are $<5 \%$, and most of them are $<1 \%$, indicating that noise-induced $\mathrm{Chl}$

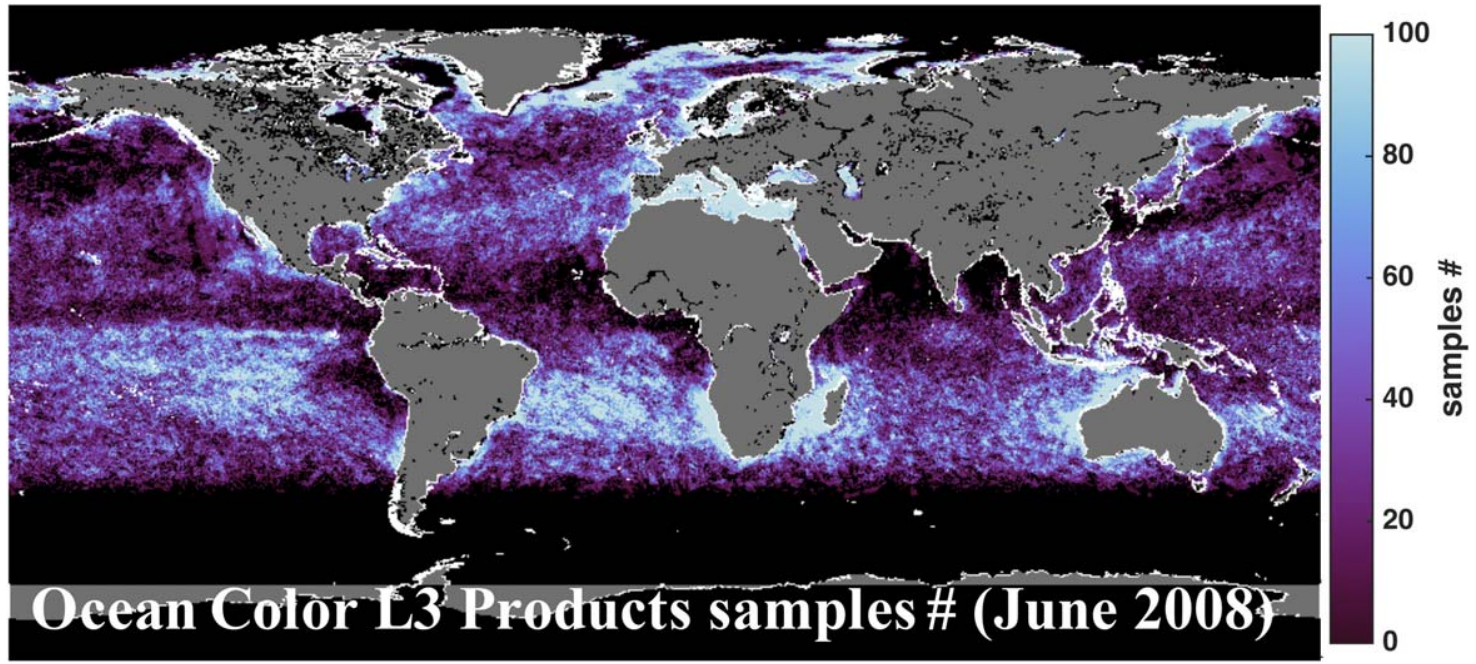

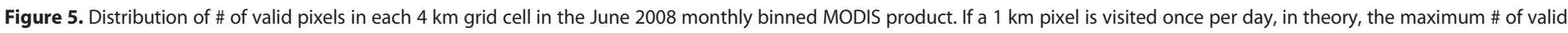
pixels from any grid cell is about $4 \times 4 \times 30=480$. The low values in the equatorial regions and in the Indian Ocean are due to persistent cloud cover, sun glint, and stray light. 


\section{QDAU Journal of Geophysical Research: Oceans}
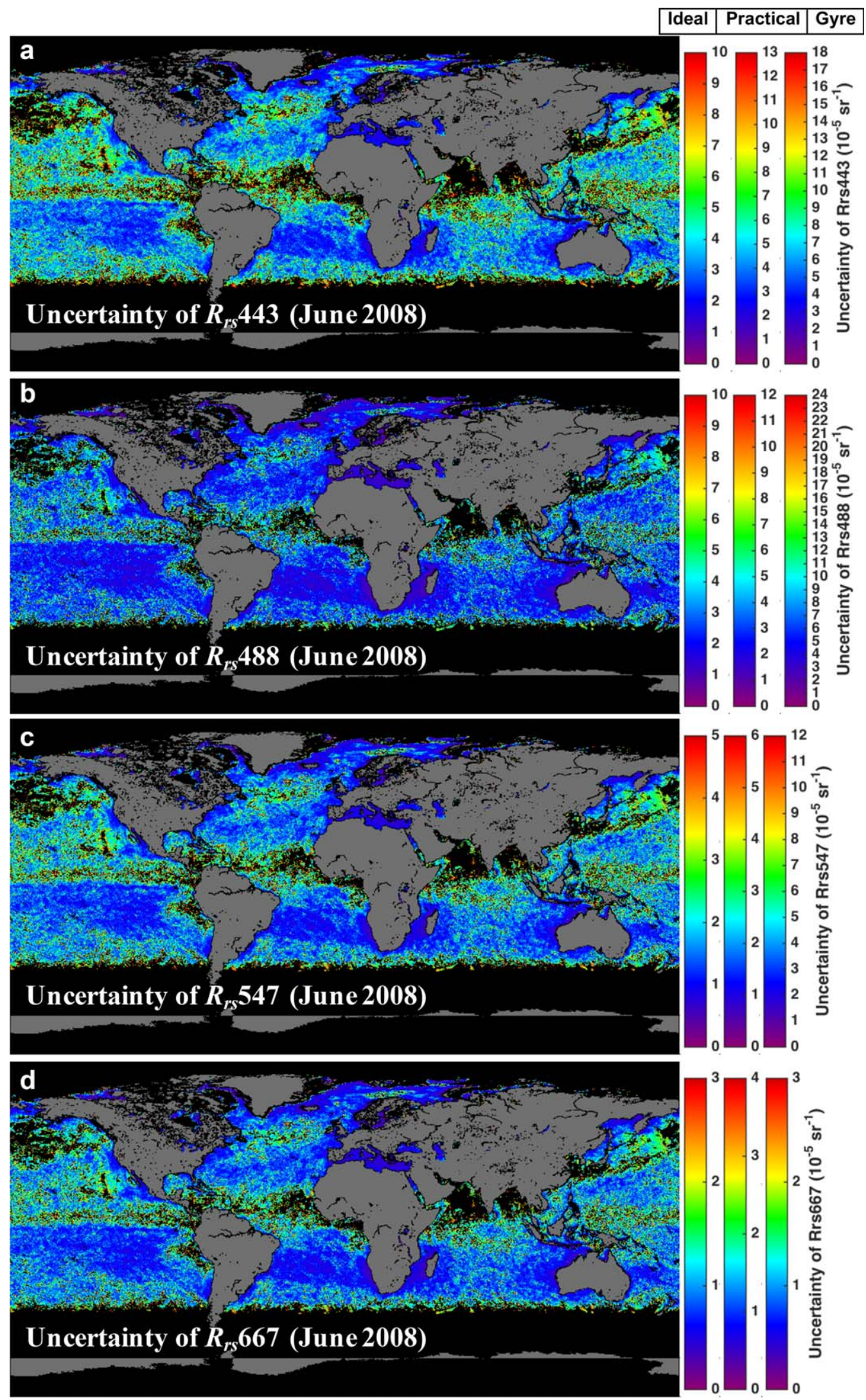

Figure 6. Distributions of $\Delta R_{r s}^{\text {total }}$ at (a) $443 \mathrm{~nm}$, (b) $488 \mathrm{~nm}$, (c) $547 \mathrm{~nm}$, and (d) $667 \mathrm{~nm}$ for the $4 \mathrm{~km}$ binned product for June 2008 . Three scenarios were used to estimate $\Delta R_{r s}$ total at pixel level: ideal (equations (2) and (5)); practical (equations (2) and (6)); and MODIS gyre estimates. The map is the same for each scenario but the scales are different as shown in the right. 


\section{QAGU Journal of Geophysical Research: Oceans}
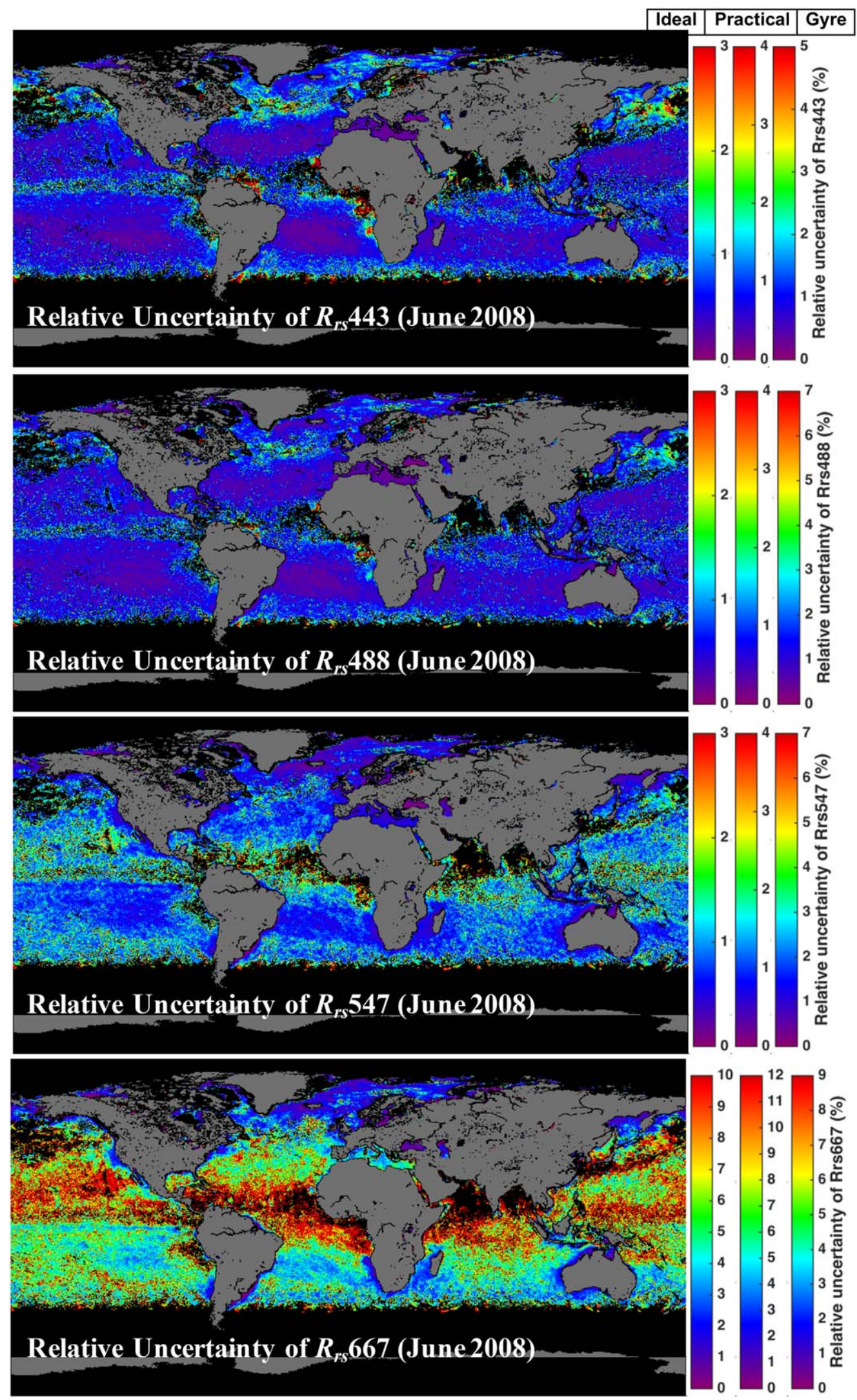

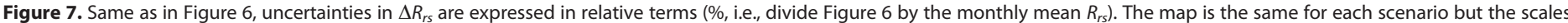
are different as shown in the right. 

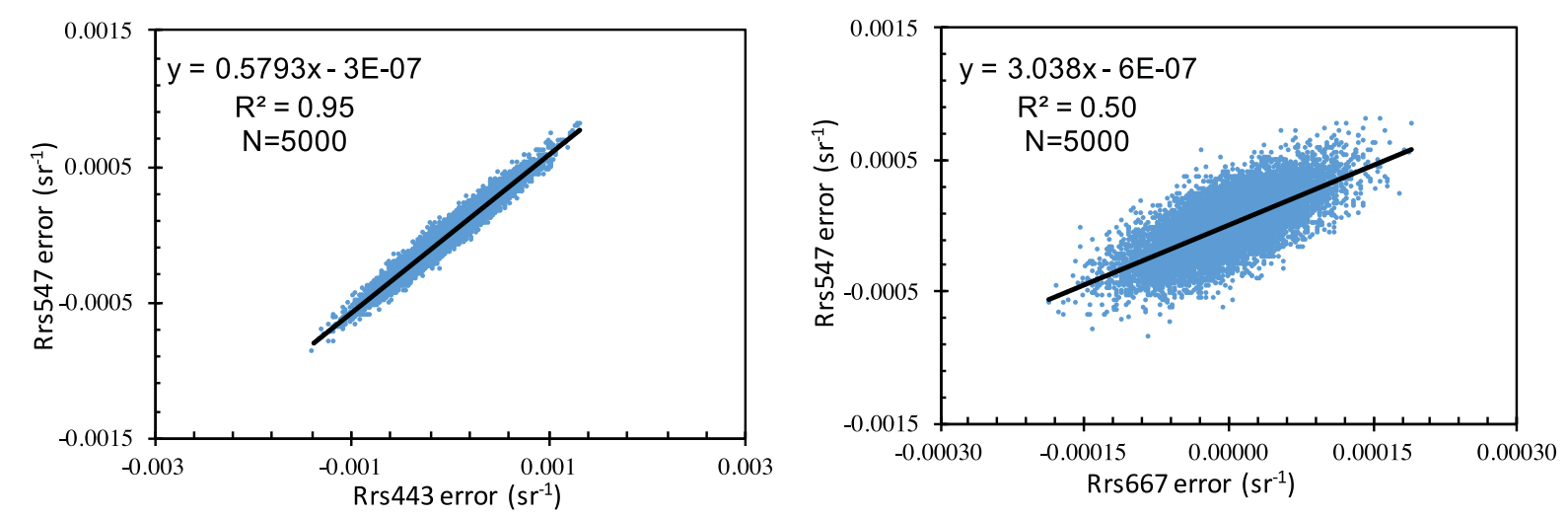

Figure 8. $R_{r s}$ errors in several spectral bands showing both dependence (the fitting lines) and independence (data scatter around the fitting lines). These errors were simulated using

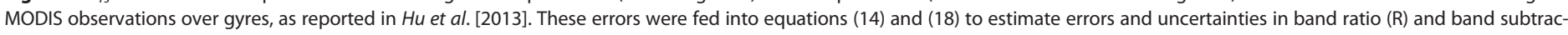
tion $(\mathrm{Cl})$, which were then used to estimate uncertainties in $\mathrm{Chl}$.
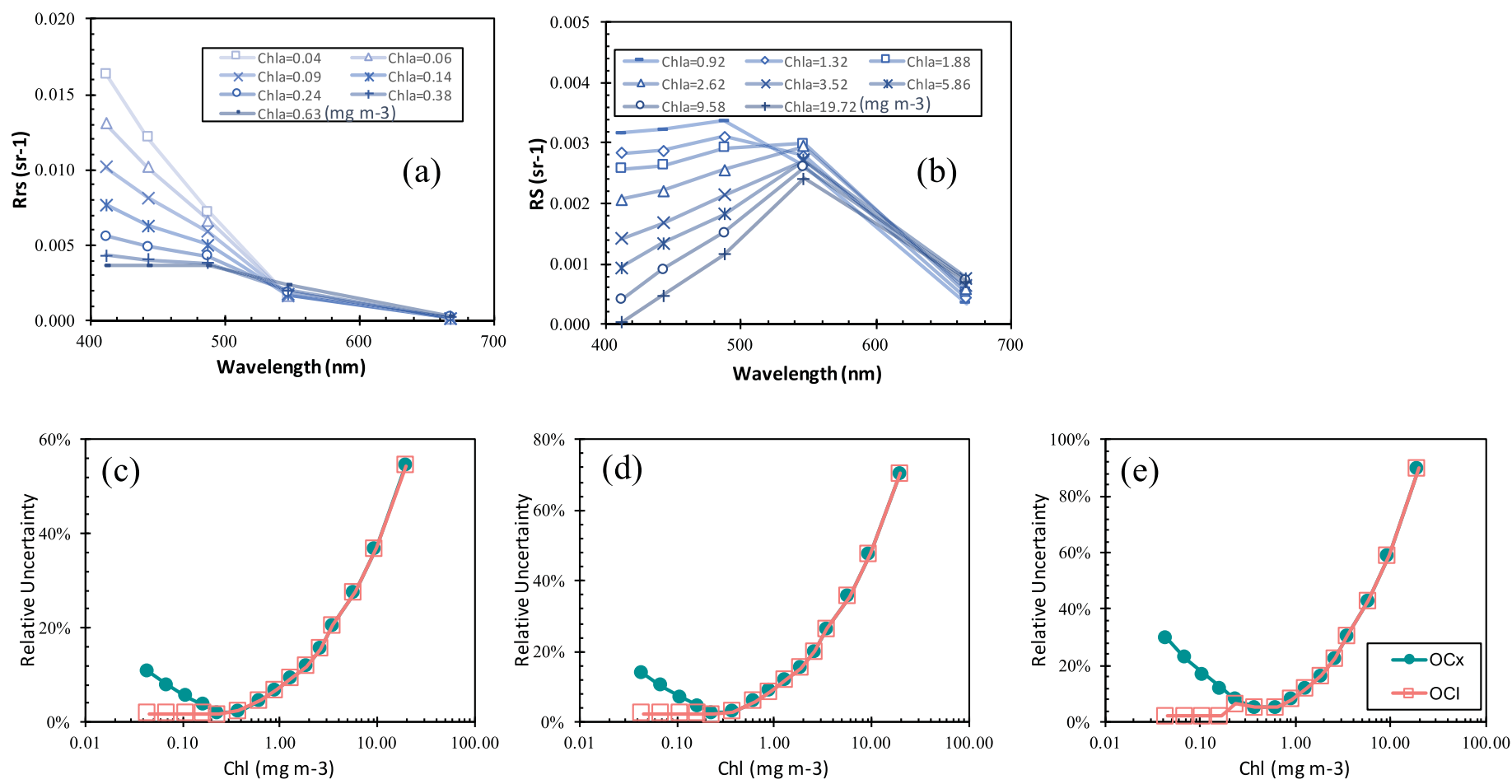

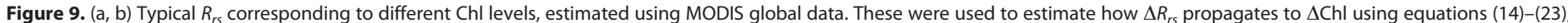

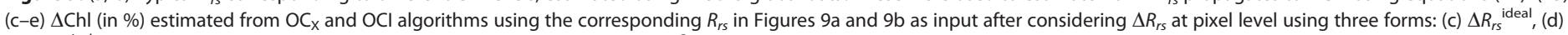
$\Delta R_{r s}{ }^{\text {practical }}$, and (e) $\Delta R_{r s}{ }^{\text {gyre }}$. Note that $\mathrm{OCl}$ switches to $\mathrm{OC}_{\mathrm{X}}$ for $\mathrm{Chl}>0.25 \mathrm{mg} \mathrm{m}^{-3}$. 


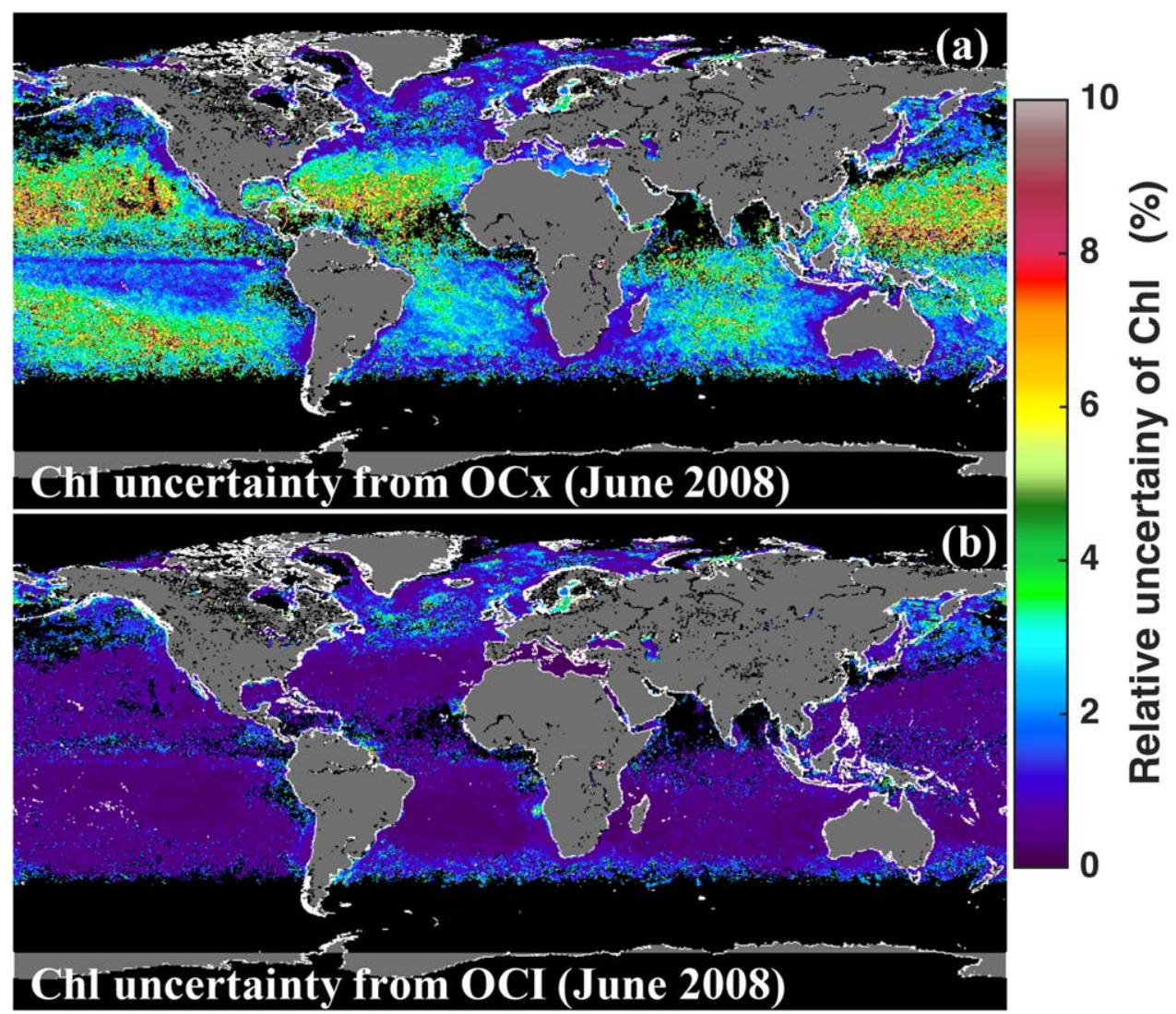

Figure 10. $\Delta \mathrm{Chl}$ (in \%) from the $4 \mathrm{~km}$ monthly $\mathrm{Chl}$ product for June 2008 , derived from (a) $\mathrm{OC}_{\mathrm{x}}$ and (b) OCl algorithms, respectively. $\Delta \mathrm{Ch}$ at pixel level is from Figure $9 \mathrm{e}$, where \# of valid observations in each $4 \mathrm{~km}$ grid cell is shown in Figure 5.

\subsection{Summary}

In short, the following findings can be summarized from the above analyses:

1. As concluded in Wang et al. [2012], SNR(NIR) of 600:1 is sufficient to perform accurate atmospheric correction, where further increases in $\mathrm{SNR}(\mathrm{NIR})$ would not lead to significant reductions in $\Delta R_{r s}{ }^{\text {atm }}$ (vis) because of inherent uncertainties in the atmospheric correction.

2. $\Delta R_{r s}{ }^{\sigma}$ (vis) induced by sensor noise in the visible bands $(\sigma)$ is $<\Delta R_{r s}{ }^{\text {atm }}$ (vis) under typical radiance input $\left(L_{\text {typ }}\right)$ as long as SNR(vis) is $>\sim 400: 1$. Therefore, for practical considerations (engineering design, cost) a sensor with SNR(vis) $\sim 400: 1$ may meet the minimal requirement, as $\Delta R_{r s}{ }^{\text {total }}$ (vis) would be dominated by $\Delta R_{r s}{ }^{\text {atm }}$ (vis) when SNR(vis) is much higher than $\sim 400: 1$. Under nontypical conditions, the number may be relaxed to 500:1 (see section 4).

3. Even when $\Delta R_{r s}{ }^{\sigma}$ (vis) were to be minimized using field measurements instead of atmospheric correction as the bound, SNR(vis) $\sim 800: 1$ would still be sufficient to meet the minimal requirement, as such SNR(vis) would lead to $\Delta R_{r s}{ }^{\sigma}$ (vis) comparable to those from the existing best field measurements.

4. Even with $\mathrm{SNR}$ (vis) $\sim 400: 1$, simulated $\Delta R_{r s}{ }^{\text {total }}$ is still lower than $\Delta R_{r s}$ gyre estimated from a sensor with much higher SNR (i.e., MODIS, SNR(NIR) 800:1 to 1000:1; SNR(vis) > 2000:1), suggesting that factors other than sensor noise play important roles in affecting $\Delta R_{r s}{ }^{\text {total }}$, which strengthen the argument that SNR(vis) of $\sim 400: 1$ may meet the minimal requirement under typical conditions.

5. $\Delta R_{r s}{ }^{\text {total }}$ would propagate to other ocean color products such as Chl through algorithm formulations and error propagation theory.

6. The above SNR considerations and product uncertainty estimates are based on individual pixels. When they are binned to $4 \mathrm{~km}$ monthly products, uncertainties in both $R_{r s}$ and Chl drop significantly as the number of valid observations in each bin is usually $\gg 1$. Consequently, $\Delta R_{r s}$ is $<5 \%$ for all blue-green bands for nearly all waters in the global oceans regardless of SNR(vis) at 400:1 or 800:1 as long as SNR(NIR) meets the requirement of 600:1. Correspondingly, $\Delta \mathrm{Chl}$ from the $\mathrm{OCl}$ algorithm is also $<5 \%$ for 
all global waters. Of course, these uncertainty estimates considered sensor noise only; when factors other than noise are considered the uncertainties may be higher.

\section{Discussion}

It may be surprising to see that a SNR(vis) of $\sim 400: 1$ (under typical input radiance) can still meet the mission requirement, at least from simulations, in retrieving $R_{r s}$ to within $5 \%$ uncertainties for blue bands and blue waters, given the fact that most published documents recommended SNR(vis) of 1000:1 or higher. Indeed, even without the sophisticated calculations a simple estimate perhaps can lead to the same conclusion: if only $10 \%$ of the total signal comes from the ocean, a SNR(vis) of 400:1 would lead to $R_{r s}$ signal to noise of 40:1, equivalent to 1:40 $(=2.5 \%)$ of $R_{r s}$ uncertainties. Actually, the current SNR(vis) specifications $\left(\mathrm{SNR}_{1}\right.$ and $\left.\mathrm{SNR}_{2}\right)$ are derived not from mission specifications on product uncertainties, but bounded by the best field measurement $\left(\Delta R_{r s}\right.$ field $)$ or best atmospheric correction $\left(\Delta R_{r s}{ }^{\text {atm }}\right)$, respectively. The reasoning for these SNRs is that if $\Delta R_{r s}{ }^{\text {field }}$ and $\Delta R_{r s}{ }^{\text {atm }}$ always exist, it is counterproductive to have very high SNR(vis) so that $\Delta R_{r s}{ }^{\sigma}$ will be lower than $\Delta R_{r s}$ field or $\Delta R_{r s}{ }^{\text {atm }}$.

Clearly, such derived $\mathrm{SNR}_{1}$ and $\mathrm{SNR}_{2}$ are not intended to meet requirements for all water types and ocean applications. For example, for waters rich in colored dissolved organic matter (CDOM), $R_{r s}$ in the blue bands can be very low ( $\sim 0.002 \mathrm{sr}^{-1}$ or even lower) [Lee et al., 2014, Figure 2a]. Then, much higher SNRs than specified here are required to reduce the relative $R_{r s}$ uncertainties in the blue bands. However, for these cases, even if $\mathrm{SNR}$ (vis) is raised to infinity, $\Delta R_{r s}{ }^{\text {atm }}$ still exists and $\Delta R_{r s}{ }^{\text {total }}$ will approach $\Delta R_{r s}{ }^{\text {atm }}$, making it impossible to have relative $R_{r s}$ uncertainties $<5 \%$ for CDOM-rich waters. Clearly, more effort is required to further improve the current state-of-the-art atmospheric correction.

Finally, by no means does this work suggest that an ocean color sensor's SNR(vis) should be set to SNR or $\mathrm{SNR}_{2}$. Rather, these numbers provide lower bounds for sensor SNR specifications. Higher SNR(vis) would lead to lower $\Delta R_{r s}{ }^{\text {total }}$, but once the SNR(vis) is higher than these lower bounds the effect of further increased SNR(vis) on the reduction of $\Delta R_{r s}{ }^{\text {total }}$ is degraded due to the dominant role of $\Delta R_{r s}{ }^{\text {atm }}$. Also, a requirement of higher SNR(vis) may limit the trade space for spatial or spectral resolutions. Nevertheless, if the trade space allows, it is useful to set SNR(vis) higher than these lower bounds, especially for applications that rely on individual images rather than on spatially/spectrally/temporally binned data.

\subsection{Applicability and Exceptions}

It is worth noting that although the above findings are based on a few assumptions which may vary in reality, such variations are unlikely to change these findings significantly.

First, simulations of atmospheric correction only considered several cases (Figure 3 ) due to the infinite number of combinations of the variable conditions in solar/viewing geometry, aerosol type, and $\tau_{\mathrm{a}}$. Of these cases, a maritime aerosol (relative humidity of $80 \%$ ) with $\tau_{\mathrm{a}}=0.1$ in the NIR was used to represent typical atmospheric conditions over the global oceans, as MODIS statistics showed $\tau_{\mathrm{a}} \sim 0.1$ over most of the open oceans. For maritime aerosol with $\tau_{\mathrm{a}} \sim 0.2, \Delta R_{r s}{ }^{\mathrm{atm}}$ is higher, but at most 30\% higher. For tropospheric aerosols, $\Delta R_{r s}{ }^{\mathrm{atm}}$ can be 2-3 times higher, but tropospheric aerosols are rare. Indeed, a higher $\Delta R_{r s}{ }^{\text {atm }}$ would argue for a lower SNR(vis) according to equation (6). Therefore, the choice of $\mathrm{SNR}_{2}(\sim 500: 1)$ should be reasonable.

Second, $\Delta R_{r s}$ field used in this study represents the best result (i.e., minimal uncertainty) from any field measurements (e.g., $1 \%$ in the blue bands for blue waters). Even though, the choice of $\mathrm{SNR}_{1}(\sim 800: 1)$ appears to be sufficient. Considering that most $\Delta R_{r s}$ field can be much higher (3-4\%) [Antoine et al., 2008], SNR derived from equation (5) can be much lower than $\mathrm{SNR}_{1}$ presented here.

Third, both sensor noise $(\sigma)$ and sensor SNR in this study were assumed to be associated with $L_{\text {typ }}$ over the Atlantic Ocean with a solar zenith angle of $45^{\circ}$ [Hu et al., 2012a]. In practice, both could be different according to the square root law, where $\sigma$ is proportional to $\operatorname{sqrt}\left(\mathrm{L} / \mathrm{L}_{\text {typ }}\right)$. The difference in $L$ may result from variable solar/viewing geometry, variable aerosols, and variable water-leaving radiance. Unless the water is extremely turbid (e.g., when atmospheric correction is switched from the NIR to shortwave infrared (SWIR) approach) [Wang and Shi, 2007], variations in L under most scenarios are at most 30-40\% [Hu et al., 2012a]. This also includes turbid atmosphere $\left(\tau_{\mathrm{a}} \sim 0.2\right)$ over Chinese marginal seas, as extremely turbid atmosphere where $\tau_{\mathrm{a}}>0.3$ is treated as clouds without ocean color retrievals. Therefore, even for moderately turbid waters with turbid atmosphere, a 20\% increase in SNR(vis) from those defined here (i.e., SNR $1 \sim 800: 1$; SNR 2 
$\sim$ 400:1) would be sufficient for the "ideal" and "practical" situations, respectively, with the former converted to $\mathrm{SNR}_{1} \sim 1000: 1$ and latter converted to $\mathrm{SNR}_{2} \sim 500: 1$.

However, all these arguments above are for conventional atmospheric correction schemes (i.e., extrapolation from the NIR to the visible) and for applications where time series of $R_{r s}, \mathrm{Chl}$, or possibly other products are used to study ocean changes and processes. For other atmospheric correction schemes that do not rely on spectral extrapolation (e.g., using optimization to derive atmosphere and ocean properties simultaneously) [Chomko et al., 2003], $\Delta R_{r s}{ }^{\text {atm }}$ may be lower than shown here, arguing for higher SNR(vis). For some applications where individual images at pixel resolution are required, such arguments are no longer valid, and other considerations of SNR requirements must be considered instead. These exceptional cases include all feature extraction applications, for example front detection [e.g., Wall et al., 2008], oil detection [Hu et al., 2009], and Sargassum mapping [Hu et al., 2015; Wang and Hu, 2016]. This is because that all these features must be delineated at pixel level and some of the features may also be at subpixel level, and a low SNR would lead to missed features (e.g., compare Figure 1a against Figure 1b) that make delineation difficult. A clear example is given in the case of Sargassum mapping. Using simulations, Hu et al. [2015] argued that a SNR of 200:1 in the red and NIR wavelengths could detect Sargassum of 1\% pixel size, while with MODIS statistics Wang and Hu [2016] showed that a SNR of 1000:1 made detection possible at $0.2 \%$ pixel size. Clearly, for these nontraditional ocean color applications, higher SNR would lead to better results, and there is perhaps no limit on the upper bound of SNR. On the other hand, if a lower SNR enables higher spatial resolution, the latter is also beneficial for such feature extraction applications.

Finally, while the estimates of $\Delta R_{r s}$ are valid at both pixel level and $4 \mathrm{~km}$ monthly product level, estimates of $\Delta \mathrm{Chl}$ in this study only considered errors induced by sensor noise and atmospheric correction where uncertainties in the $\mathrm{Chl}$ algorithms were not included. In other words, $\Delta \mathrm{Chl}$ presented here assumed error-free $\mathrm{Chl}$ algorithms. In reality, this is certainly not possible. When the algorithm uncertainties are also included, because these uncertainties may range between 10 and 50\% [e.g., Gordon, 1990], following the square root law (equation (2)), $\Delta \mathrm{Chl}$ at pixel level would be much higher than presented in Figure 9. However, as long as the algorithm uncertainties come from random errors rather than systematic errors, $\triangle \mathrm{Chl}(\mathrm{OCl}$ algorithm) in the $4 \mathrm{~km}$ monthly product would still be $<5 \%$ for nearly all locations.

\subsection{Implications for Sensor Design}

Unlike all previous recommendations for ocean color sensor design, a useful finding from this study is that once SNR(NIR) is at least 600:1, SNR(vis) can be much lower than 1000:1. Even after taking into account of the variable $L$ (as opposed to $L_{\text {typ }}$ used here), for practical considerations a SNR(vis) of 500:1 can be set as a minimal bound for traditional applications. Given the fact that future ocean color missions such as The PreAerosols Clouds and ocean Ecosystems (PACE) and Geostationary for Coastal and Air Pollution Events (GeoCAPE) are already designed to have SNR(vis) > 1000:1, the question then becomes so what-why bother arguing for a lower SNR(vis) as these sensors will have SNR(vis) > 1000:1 anyway?

Indeed, there are several implications from the findings here. First, they provide scientific support for a trade between SNR(vis) and other factors (e.g., sensor size, cost). Second, they support the use of nonocean color sensors for ocean color applications. For example, Hyperspectral Imager for the Coastal Ocean (HICO) SNR in the blue-green wavelengths is 300:1 to 500:1 [Lucke et al., 2011], and Landsat-8 OLI SNR in the blue-green wavelengths is $300: 1$ to 350:1 [Pahlevan et al., 2014]. They are not significantly lower than $\mathrm{SNR}_{2}(400: 1)$ defined here. Therefore, once SNR(NIR) is increased to $600: 1$ through $5 \times 5$ or $9 \times 9$ smoothing because atmosphere is generally more homogenous than the ocean [e.g., Barnes et al., 2014], ocean color products can be derived from HICO and OLI at raw pixel resolution. Then, for the same reason, for future sensor design targeted for high spatial resolution applications, SNR(vis) can be set at $\sim 500: 1$ as long as SNR(NIR) approaches 600:1 through either spatial smoothing or spectral binning.

\section{Conclusion}

The most significant finding in this study is that, generally for open oceans, SNR(vis) can be lower than 1000:1 for an ocean color sensor. This finding is based on the fact that assuming error-free radiometric calibration, most uncertainties in the satellite-retrieved $R_{r s}$ originate from the imperfect atmospheric correction, and further increases in SNR(vis) would not lead to significant reductions in $\Delta R_{r s}$. In this work, only these two 
uncertainty sources (i.e., sensor noise and atmospheric correction) were considered, while in reality other sources (e.g., instrument artifacts, errors in ancillary data, imperfect bio-optical inversion algorithms, etc.) also impact data product uncertainty. However, unless these other sources depend on sensor noise, they do not invalidate the argument of the minimal SNR requirement here. Another finding is that the $\Delta R_{r s}<5 \%$ requirement can be easily met for most global ocean waters in the $4 \mathrm{~km}$ monthly data products, where $\Delta \mathrm{Chl}$ from the $\mathrm{OCl}$ algorithm is also $<5 \%$, sufficient for most applications to address ocean changes in response to climate variability. Similar to the argument for a minimal SNR requirement, this finding is based only on noise and atmospheric correction induced errors without considering other error sources (e.g., imperfect bio-optical inversion algorithms), therefore it should not be considered as being applicable everywhere unless uncertainties from other sources are well understood. Finally, although the findings about SNR requirements may not be extended to some nontraditional applications (e.g., feature extraction), they support the argument to trade SNR for other requirements (e.g., spatial and spectral resolutions) of ocean sensor design. However, these results only provide lower bounds of SNR, and higher SNR may still be pursued if trade space allows, especially for coastal CDOM-rich dark waters and nontraditional ocean color applications.

\section{Notations}

$\delta \quad \quad \quad \quad$ a single value representing error from the hypothetical "truth."

$\sigma \quad$ measurement noise, defined as the standard deviation of normal $\delta$ distribution.

$\mathrm{NE} \Delta \mathrm{L} \quad$ noise-equivalent radiance $(\mathrm{NE} \Delta \mathrm{L})$, used interchangeably with $\sigma$ in this study.

SNR signal-to-noise ratio, defined as the ratio of sensor signal $(L)$ and $\sigma$.

SNR(NIR) SNR in the near-infrared bands that are used for atmospheric correction.

SNR(vis) SNR in the visible bands that have a direct impact on sensor $\sigma$ (vis).

$L_{\text {typ }} \quad$ typical sensor signal, estimated from MODIS measurements over the Atlantic with a solar zenith angle of $45^{\circ}$.

$\Delta \quad$ uncertainty in a measured or estimated property, or its probability in approaching the truth. Technically, it is defined as the standard deviation of the error distribution. A single measured or estimated value has a $68 \%$ likelihood to have its error $<\Delta$.

$\rho_{\mathrm{wn}} \quad$ normalized water-leaving reflectance, dimensionless.

$R_{r s} \quad$ remote sensing reflectance, $\mathrm{sr}^{-1} ; R_{r s}=\rho_{\mathrm{wn}} / \pi$.

$\Delta R_{r s}{ }^{\text {atm }} \quad \Delta R_{r s}$ in the visible bands originated from atmospheric correction.

$\Delta R_{r s}{ }^{\sigma} \quad \Delta R_{r s}$ in the visible bands originated from $\sigma$ (vis) (i.e., directly related to SNR(vis)).

$\Delta R_{r s}{ }^{\text {total }} \quad \Delta R r s$ in the visible bands originated from both $\Delta R_{r s}{ }^{\text {atm }}$ and $\Delta R_{r s}{ }^{\sigma}$.

$\Delta R_{r s}$ field minimal $\Delta$ Rrs from field measurements, used in this study as a reference to bound the SNR(vis) selection.

$\Delta R_{r s}$ gyre $\quad \Delta R_{r s}$ estimated from MODIS/Aqua measurements over ocean gyres, representing realistic $\Delta R_{r s}$ from ocean color measurements.

Acknowledgments

All satellite data used in this study were obtained from NASA (https:// oceancolor.gsfc.nasa.gov). Simulated data are available from the authors upon request. The support of China's National Satellite Oceanic Application Center, the National Key Research and Development Program of China (2016YFC1400905 and 2016YFA0601201) and Key project of National Natural Science Foundation of China (No.41431176) (Qi) is greatly appreciated. The views, opinions, and findings contained in this paper are those of the authors and should not be construed as an official NOAA or U.S. Government position, policy, or decision. We thank NASA for providing MODIS data. We are indebted to two anonymous reviewers who provided extensive comments and suggestions to help improve this manuscript.
$\Delta \mathrm{Chl}$

$\mathrm{OC}_{\mathrm{x}}$

$\mathrm{OCl} \quad$ a hybrid chlorophyll retrieval algorithm to combine band subtraction and band ratio.

$\mathrm{SNR}_{1} \quad \mathrm{SNR}$ (vis) determined through forcing $\Delta R_{r s}{ }^{\sigma}$ to equal to $\Delta \mathrm{Rrs}^{\text {field }}$.

$\mathrm{SNR}_{2} \quad \mathrm{SNR}$ (vis) determined through forcing $\Delta R_{r s}{ }^{\sigma}$ to equal to $\Delta \mathrm{Rrs}^{\text {atm }}$.

\section{References}

Antoine, D., A. Morel, H. R. Gordon, V. F. Banzon, and R. H. Evans (2005), Bridging ocean color observations of the 1980s and 2000s in search of long-term trends, J. Geophys. Res., 110, C06009, doi:10.1029/2004JC002620.

Antoine, D., F. d'Ortenzio, S. B. Hooker, G. Bécu, B. Gentili, D. Tailliez, and A. J. Scott (2008), Assessment of uncertainty in the ocean reflectance determined by three satellite ocean color sensors (MERIS, SeaWiFS and MODIS-A) at an offshore site in the Mediterranean Sea (BOUSSOLE project), J. Geophys. Res., 113, C07013, doi:10.1029/2007JC004472.

Bailey, S. W., and P. J. Werdell (2006), A multi-sensor approach for the on-orbit validation of ocean color satellite data products, Remote Sen. Environ., 102, 12-23.

Barnes, B. B., and C. Hu (2015), Cross-sensor continuity of satellite-derived water clarity in the Gulf of Mexico: Insights into temporal aliasing and implications for long-term water clarity assessment, IEEE Trans. Geosci. Remote Sens., 53, 1761-1772.

Barnes, B. B., C. Hu, K. L. Holekamp, S. Blonski, B. A. Spiering, D. Palandro, and B. Lapointe (2014), Use of Landsat data to track historical water quality changes in Florida Keys marine environments, Remote Sens. Environ., 140, 485-496.

Behrenfeld, M. J., et al. (2001), Biospheric primary production during an ENSO transition, Science, 291, 2594-2597.

Cannizzaro, J., C. Hu, K. L. Carder, C. R. Kelble, N. Melo, E. M. Johns, G. A. Vargo, and C. A. Heil (2013), On the accuracy of SeaWiFS ocean color data products on the West Florida Shelf, J. Coastal Res., 29(6), 1257-1272, doi:10.2112/JCOASTRES-D-12-00223.1. 
Chomko, R. M., H. R. Gordon, S. Maritorena, and D. A. Siegel (2003), Simultaneous retrieval of oceanic and atmospheric parameters for ocean color imagery by spectral optimization: A validation, Remote Sens. Environ., 84, 208-220.

Feng, L., and C. Hu (2016), Comparison of valid ocean observations between MODIS Terra and Aqua over the global oceans, IEEE Trans. Geosci. Remote Sens., 54, 1575-1585, doi:10.1109/TGRS.2015.2483500.

Gordon, H. R. (1990), Radiometric considerations for ocean color remote sensors, Appl. Opt., 29, 3228-3236.

Gordon, H. R. (1997), Atmospheric correction of ocean color imagery in the Earth Observing System era, J. Geophys. Res., 102, 17,081-17,106.

Gordon, H. R., and M. Wang (1994), Retrieval of water-leaving radiance and aerosol optical thickness over the oceans with SeaWiFS: A preliminary algorithm, Appl. Opt., 33, 443-452.

Gregg, W. W., N. W. Casey (2004), Global and regional evaluation of the SeaWiFS chlorophyll dataset, Remote Sens. Environ., 93, 463-479.

Gregg, W. W., N. W. Casey, and C. R., McClain (2005), Recent trends in global ocean chlorophyll, Geophys. Res. Lett., 32, L03606, doi:10.1029/ 2004 GL021808.

Hooker, S. B., W. E. Esaias, G. C. Feldman, W. W. Gregg, and C. R. McClain (1992), An overview of SeaWiFS and ocean color, in NASA Tech. Memo., vol. 104566, Natl. Aeronaut. and Space Admin., Goddard Space Flight Cent., Greenbelt, Md.

Hu, C., X. Li, W. G. Pichel, and F. E. Muller-Karger (2009), Detection of natural oil slicks in the NW Gulf of Mexico using MODIS imagery, Geophys. Res. Lett., 36, L01604, doi:10.1029/2008GL036119.

Hu, C., L. Feng, Z. Lee, C. O. Davis, A. Mannino, C. R. McClain, and B. A. Franz (2012a), Dynamic range and sensitivity requirements of satellite ocean color sensors: Learning from the past, Appl. Opt., 51, 6045-6062.

Hu, C., Z. Lee, and B. Franz (2012b), Chlorophyll $a$ algorithms for oligotrophic oceans: A novel approach based on three-band reflectance difference, J. Geophys. Res., 117, C01011, doi:10.1029/2011JC007395.

$\mathrm{Hu}, \mathrm{C}$., L. Feng, and Z. Lee (2012c), Evaluation of GOCl sensitivity for at-sensor radiance and GDPS-retrieved chlorophyll- $a$ products, Ocean Sci. J., 47, 279-385.

Hu, C., L. Feng, and Z. Lee (2013), Uncertainties of SeaWiFS and MODIS remote sensing reflectance: Implications from clear water measurements, Remote Sens. Environ., 133, 168-182.

Hu, C., L. Feng, R. F. Hardy, and E. J. Hochberg (2015), Spectral and spatial requirements of remote measurements of pelagic Sargassum macro algae, Remote Sens. Environ., 167, 229-246, doi:10.1016/j.rse.2015.05.022.

IOCCG (2010), Atmospheric correction for remotely-sensed ocean-colour products, in Reports of International Ocean-Color Coordinating Group, edited by M. Wang, No. 10, Dartmouth, Canada.

IOCCG (2012), Mission requirements for future ocean-colour sensors, in Reports of the International Ocean-Colour Coordinating Group, edited by C. R. McClain, and G. Meister, No. 13, Dartmouth, Canada.

Lee, Z., N. Pahlevan, Y. Ahn, S. Greb, and D. M. Donnell (2013), Robust approach to directly measuring water-leaving radiance in the field, Appl. Opt., 52(8), 1693-1701.

Lee, Z., S. Shang, C. Hu, and G. Zibordi (2014), Spectral interdependence of remote-sensing reflectance and its implications on the design of ocean color satellite sensors, Appl. Opt., 53, 3301-3310.

Lucke, R. L., M. Corson, N. R. Mcglothlin, S. D. Butcher, D. L. Wood, D. R. Korwan, R. R. Li, W. A. Snyder, C. O. Davis, and D. T. Chen (2011), Hyperspectral Imager for the Coastal Ocean: Instrument description and first images, Appl. Opt., 50(11), 1501-1516.

Maritorena S., O. Hembise Fanton d'Andon, A. Mangin, and D. A. Siegel (2010), Merged satellite ocean color data products using a bio-optical model: Characteristics, benefits and issues, Remote Sens. Environ., 114(8), 1791-1804.

Marrari, M., C. Hu, and K. Daly (2006), Validation of SeaWiFS chlorophyll- $a$ concentrations in the Southern Ocean: A revisit, Remote Sens. Environ., 105, 367-375.

McClain, C. R (2009), A decade of satellite ocean color observations, Annu. Rev. Mar. Sci., 1, 19-42.

McClain, C. R., G. C. Feldman, and S. B. Hooker (2004), An overview of the SeaWiFS project and strategies for producing a climate research quality global ocean bio-optical time series, Deep Sea Res., Part II, 51, 5-42.

Mélin, F., G. Zibordi, and J.-F. Berthon (2007), Assessment of satellite ocean color products at a coastal site, Remote Sens. Environ., 110, $192-215$.

Moore, T. S., J. W. Campbell, and H. Feng (2015), Characterizing the uncertainties in spectral remote sensing reflectance for SeaWiFS and MODIS-Aqua based on global in situ matchup data sets, Remote Sens. Environ., 159, 14-27.

Morgan, M. G., and M. Henrion (1990), Uncertainty: A Guide to Dealing With Uncertainty in Quantitative Risk and Policy Analysis, chap. 8, 332 pp., Cambridge Univ. Press, The Edinburgh Building, Cambridge, U. K.

O’Reilly, J. E., S. Maritorena, B. G. Mitchell, D. A. Siegel, K. L. Carder, S. A. Garver, M. Kahru, and C. R. Mcclain (1998), Ocean color chlorophyll algorithms for SeaWiFS, J. Geophys. Res., 103, 24,937-24,953.

Pahlevan, N., Z. Lee, J. Wei, C. B. Schaaf, J. R. Schott, and A. Berk (2014), On-orbit radiometric characterization of OLI (Landsat-8) for applications in aquatic remote sensing, Remote Sens. Environ., 154, 272-284.

Wall, C., F. E. Muller-Karger, M. A. Roffer, C. Hu, W. Yao, and M. E. Luther (2008), Satellite remote sensing of surface oceanic fronts in coastal waters off west-central Florida, Remote Sens. Environ., 112, 2963-2976.

Wang, M. (2007), Remote sensing of the ocean contributions from ultraviolet to near-infrared using the shortwave infrared bands: Simulations, Appl. Opt., 46, 1535-1547.

Wang, M., and C. Hu (2016), Mapping and quantifying Sargassum distribution and coverage in the Central West Atlantic using MODIS observations, Remote Sens. Environ., 183, 350-367, doi:10.1016/j.rse.2016.04.019.

Wang, M., and W. Shi (2007), The NIR-SWIR combined atmospheric correction approach for MODIS ocean color data processing, Opt. Express, 15, 15,722-15,733.

Wang, M., and S. Son (2016), VIIRS-derived chlorophyll-a using the ocean color index method, Remote Sens. Environ., 182, 141-149.

Wang, M., S. Son, and W. Shi (2009), Evaluation of MODIS SWIR and NIR-SWIR atmospheric correction algorithms using SeaBASS data, Remote Sens. Environ., 113(3), 635-644.

Wang, M., H. R. Gordon, and S. Maritorena (2012), Ocean science requirements supplement: Parameter ranges, regrieval sensitivities to noise, and signal-to-noise requirements for hyperspectral $(5 \mathrm{~nm}$ ) bands (sections A.2 and A.3), in Appendix A of the PACE Mission Science Definition Team Report by Carlos et al., NASA Goddard Space Flight Cent., Greenbelt, Md.

Zibordi, G., F. Melin, and J. F. Berthon (2006), Comparison of SeaWiFS, MODIS, and MERIS radiometric products at a coastal site, Geophys. Res. Lett., 33, L06617, doi:10.1029/2006GL025778.

Zibordi, G., J.-F. Berthon, F. Mélin, D. D'Alimonte, and S. Kaitala (2009), Validation of satellite ocean color primary products at optically complex coastal sites: Northern Adriatic Sea, Northern Baltic Proper and Gulf of Finland, Remote Sens. Environ., 113, $2574-2591$. 